Article

\title{
The Emerging Global Tourism Geography-An Environmental Sustainability Perspective
}

\section{Paul Peeters * and Martin Landré}

NHTV Breda University of Applied Sciences, P.O. Box 3917, 4800 DX Breda, The Netherlands; E-Mail: landre.m@nhtv.nl

* Author to whom correspondence should be addressed; E-Mail: peeters.p@nhtv.nl;

Tel.: +31-76-5332203; Fax: +31-76-5332205.

Received: 17 November 2011; in revised form: 13 December 2011 / Accepted: 13 December 2011 / Published: 28 December 2011

\begin{abstract}
The current development of tourism is environmentally unsustainable. Specifically, tourism's contribution to climate change is increasing while other sectors are reducing their greenhouse gas emissions. This paper has two goals: reveal the main structural cause for tourism's emission growth and show the consequences thereof for (mitigation) policies. It is reasoned that the main cause for tourism's strong emission growth is the time-space expansion of global tourism behavior. Contemporary tourism theory and geography fail to clearly describe this geographical development, making it difficult to understand this expansion and develop effective policies to mitigate environmental impacts. Therefore, this paper explores some elements of a 'new tourism geography' and shows how this may help to better understand the causes of the environmentally unsustainable development of tourism with respect to climate change and devise mitigation policies.
\end{abstract}

Keywords: tourism; geography; transport; climate change; sustainable development

\section{Introduction}

If climate change is a proxy for the environmental issues related to tourism, then it has been clearly demonstrated that tourism is developing unsustainably. Several studies have shown that in the 2050s, tourism related greenhouse gas emissions will be larger than global emissions and will surpass the 
global emission ceiling that safeguards against 'dangerous' climate change [1-3]. Proposed mitigation of tourism's greenhouse gas emissions focuses mainly on technological improvements such as improving the energy efficiency of accommodations and transport modes, using low carbon fuels (mainly bio-fuels for aviation and electric cars for road transport), and off-setting the emissions through funding reductions in other sectors [4-6]. Using these measures, the sector envisages reducing total emissions by $50 \%$ by 2035 [4], but this ambition is deemed un-realistic [1,7], unless a strong change in tourism transport modes and distances is effected [8,9]. This implies that the trend towards globalization of tourism patterns should be reversed, including reversal of the trends towards travelling farther, more often, for shorter stays and more frequently by air transport.

The aim of this paper is to develop some elements of a 'new tourism geography' and, based on this, show the importance of distance in tourism and its sustainable development. The main questions addressed in this paper are the following: (1) if current tourism is developing sustainably; (2) if geographies/studies are well equipped to assist policy makers in creating sustainable tourism development; and (3) how the geography of tourism has to change to develop tourism sustainably? To find answers, first some geographical mechanisms/relations are explored, providing tools to fill in data gaps in global databases of international and domestic tourism flows. This database is used to find the implications of changes in travel distances on greenhouse gas emissions. Transport modes are related to distances as travel over more than $1,500 \mathrm{~km}$ tends to be almost exclusively air transport, while at shorter distances all modes compete, though under $200 \mathrm{~km}$ air transport's share approaches zero. Distance is the most important driver for $\mathrm{CO}_{2}$ emissions as at long distances the large volume of travel (passenger kilometers) combines with higher average emissions per pkm.

\section{Tourism and Transport Geography}

Definitions of geography, range from rather general- "the study of the world, its people, and the interactions between the two" [10] — to more specific - "the study of the earth and its features and of the distribution of life on the earth, including human life and the effects of human activity" [11]). The main elements in these definitions are the interactions between the physical and living world, including humans. Within geography, Williams defines tourism geography as part of human geography [12] but observes that it has never gained a serious position for academic investigation as tourism is considered to be "a fun-related activity" (p. 19 in [12]). According to Mitchell [13], tourism geography has its focus on the spatial and environmental development of destinations, including access, but not specifically mobility. This description corresponds with the assertion that the main element of human (tourism) geography is places that are defined as "not only merely bounded spaces or locations, but ... also settings (or locales) in which social relations and identities are constituted and in which is developed a sense of place" (p. 185 in [12]). Currently, the destination seems to be the main focus of tourism geography, which is also clear from the contents of some major texts on tourism geography [12,14].

In 1976, Miossec published a geography-based tourism theory that gave a prominent place to transport [15]. He stressed the role of transport, transport technology, travel time, travel distance and mode choice in destination choice. His mapping of tourism from Germany, France, and the United Kingdom showed clearly that for larger distances the number of trips is lower. On page 19, Miossec 
presents a distance decay graph for Germany [15]. He also presents schematic graphs showing the relations between distance, travel time and travel cost for different transport modes (p. 37, Figure 12 in [15]). Another early description of tourism geography was published by Williams and Zelinsky in 1970 [16]. They reject a rather basic hypothesis for tourism flows, the 'hypothesis of indifference' (p. 556 in [16]), that assumes that if a destination receives $X$ percent of global international tourists, it should receive the same $\mathrm{X}$ percent of all departures for each country in the world. This hypothesis fully ignores the role of transportation, distance, cost, and travel time, and it is not surprising that it did not hold against empirical evidence [16]. Williams and Zelinsky also reject the hypothesis of reciprocity, which assumes that a strong tourism flow from A to B will always generate a "reflexive, or counterflow" (p. 564 in [16]). A third hypothesis, the idea that destinations with a lower cost of living will generate the most arrivals, is only partly confirmed by empirical analysis (p. 566 in [16]). Only two hypotheses appear to be valid to them. The first positively relates tourism flows to tourism attraction (e.g., 'desirable climatic characteristics, scenic attractions, cultural and historical features, sports, shopping facilities, night life'). The second hypothesis positively relates tourism flows to international connectivity (e.g., commercial, business, migration, cultural relations and political linkages) (pp. 564-565 in [16]).

The obvious roles of transport and distance have not been tested because of "the absence of data on points of origin for tourists from large countries (e.g., the United States and Scandinavia) and a similar lack of data for destination points" (pp. 563-564 in [16]). Unfortunately, this theoretical work has not been further developed into a strong theoretical base [14]. An exemption is the tourism area life cycle model [17] that originated in geography but which is often treated in an aspatial fashion [18]. The lack of theoretical progress on spatial interaction properties of tourism has arguably resulted in tourism geography being mainly focused on the development of destinations, while generally ignoring the (places of) demand and the links between the two. This skewed focus has produced a lack of recognition within the wider scientific community of the importance of tourism geography $[12,19,20]$. Most textbooks on tourism management and economics see transport as a derived demand with a cost in terms of money and time (e.g., [21]). These books often ignore the fact that transport is an intrinsic part of any travel, also mentally (e.g., [22]). Furthermore, these books also ignore the many interactions between the transport system and the (in-)ability of certain destinations and certain forms of tourism to develop. Even some tourism geography texts pay little attention to the role of transport and transport infrastructure [12,14,19]. An exemption forms a textbook by C. Michael Hall [23], that extensively discusses tourism mobility and models taken from transport and behavioral geography.

Climate mitigation studies conclude that policies may increase costs of tourism and reduce its economic growth in case of carbon taxes [24-27] or oil price increases [28], though other studies find no significant impacts [29] or believe that second order effects like a mode shift from aviation to the car, may even increase overall emissions when taxing aviation. Unfortunately, most of these studies fail to include important parts of the tourism system, e.g., by just dealing with air transport or international tourism thus failing to acknowledge shifts to other transport modes, or domestic tourism. For instance, Becken et al. [28] state on page 135 that the main challenge "that global interactions within the tourism sector (e.g., substitution between destination countries) are not well accounted for" because of "current limitations of global datasets". We provide such a geographical database. 
The most fundamental problem of current tourism geography seems to be the unit of geographical scale. Generally, geographical data are based on the nation. Unfortunately, that causes problems as nations' sizes in terms of population, land area and economy vary by up to eight orders of magnitude (e.g., Monaco versus China). This problem of differing scales already has been observed in the 1970s $[15,16]$ but has yet to be satisfactorily solved. Derived from this geographical scale problem are two other issues: the divide between international and domestic tourism and the preoccupation with air transport. These two issues lead to many misunderstandings and biases. For instance, the idea that Europe is the most important tourism destination [30,31] is incorrect as China receives annually far more tourists if 1.6 billion domestic tourists [32] were included. The different scales of nations cause that almost all tourist trips by citizens of Monaco are 'international', and most trips by Australians are 'domestic'. But this large seemingly large difference is not representative for the overall difference in travel patters. Most likely, overall travel patterns will be relatively similar in terms of trips, distance distribution, costs and travel times, with the main distinctions being caused by differences in transport infrastructure and the geographical distribution of tourism attractions. More generally, the divide between domestic and international tourism tends to cause an overvaluation of relatively easily measurable international tourism and ignorance of more difficult to measure domestic tourism [14]. Even though UNWTO (United Nations World Tourism Organization) has recently updated the standard of their statistical compendium to include a section on domestic tourism in 2010 (see [33]), this has only resulted in domestic tourism data for just 14 of approximately 210 countries/protectorates recognized in the Tourism Factbook [34].

An important caveat of the focus on international tourism is the overvaluation of the role of aviation in tourism. For example, a recently published advanced tourism-energy model [35] ignores transportation by defining the tourism system in terms of energy system, number of tourists, waste, revenues, and accommodations (supply system) only. Also, a well-known textbook about the tourism economy dedicates only one chapter to aviation [36], and ignores the role of other modes. This is unfortunate as these other modes serve over $80 \%$ of all tourism trips in the world [8]. Transport geography is seen as "a sub-discipline of geography concerned about movements of freight, people and information: It seeks to link spatial constraints and attributes with the origin, the destination, the extent, the nature and the purpose of movements" (Rodrigue [37], p. 5). Several concepts from transport geography will be used to overcome the main problems of current tourism theory and geography. In this way, a Global Tourism Transport Database (GTTD, see Section 3) has been developed that covers all tourist trips (international and domestic) and provides information on travel distances. Furthermore, the GTTD not only contains all flows between countries, but also aggregates these to 18 world regions as an alternative to the problematic geographical unit of the 'nation state'.

\section{The GTTD and Elements of a New Tourism Geography}

Only a few attempts have been made to create a global tourism flow database; one example is a database developed by Bigano et al. [38]. As this database uses rather old data_-generally 1995 data from the World Resources Institute-NHTV CSTT created one with 2005 as base year: the Global Tourism Transport Database (GTTD), which is based on UNWTO data [39]. In this database, the UNWTO 'Arrivals of non-resident tourists in all types of accommodation establishments, by country 
of residence' are used when available. These arrivals are given per country of destination. The number of countries of origin per country of destination distinguished by UNWTO data varies over the destination countries between just a few up to more than 100. Remaining countries of origin are given as aggregates per world region (e.g., 'Other Europe', 'Other South-East Asia' or 'Other World'). However, it appears that these 'other' places of residence represented just 3\% of the total number of arrivals in the database and we have simply removed them instead of trying to redistribute them over the designated regions. In some cases (e.g., Comoros, Libya), no data for 2005 were available, and 2004 data were used instead. Also, corrections (reductions) were applied to flows between neighboring countries where in some cases large numbers of same-day arrivals were incorrectly counted as 'tourist' arrivals, largely inflating numbers. We consulted national data for this correction where available. The database contains 12,118 country-pairs for a total of 223 countries with international flows totaling to 735 million, which is $2.6 \%$ short of the officially published figure of 755 million for 2005 [40]. Furthermore, the data are presented by using world regions as defined in Figure 1, to create more equal geographic entities as nations.

Figure 1. The world regions (source IMAGE-team [41]).

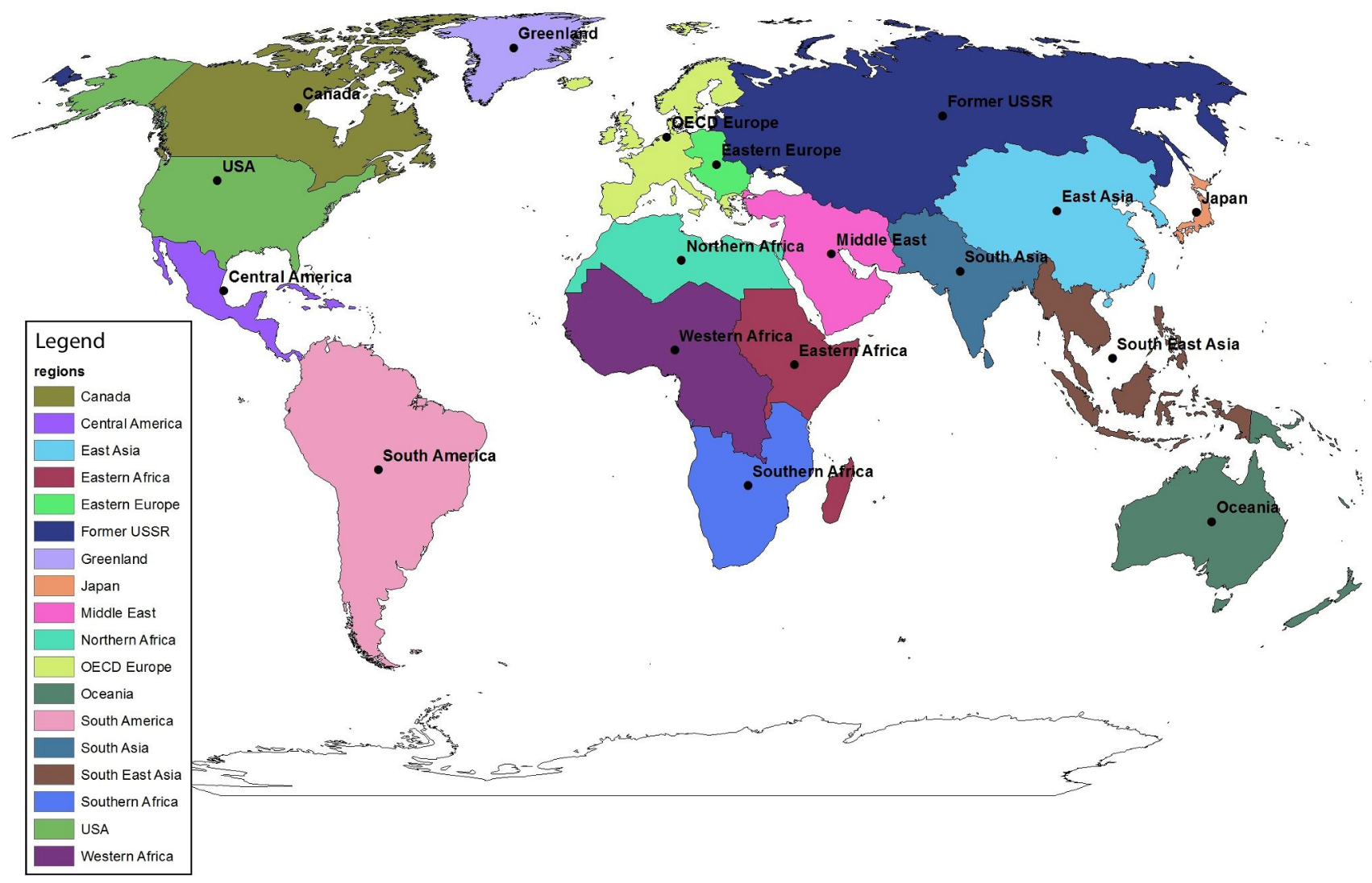

The UNWTO data fail to provide consistent and complete information about domestic tourism, transport mode and distances travelled. The 'transport' element of the GTTD was added by calculating the 'great circle distance' between all countries using the "Great Circle Mapper" [42] and the airport codes for the main airport of each country. For country pairs between neighboring countries with at least one very large country, we replaced the airport in the large country with one nearer to the border between the two countries. This correction kept large numbers of arrivals from being assigned to too 
large distances. A total of international distances (round-trip) of $3.720 \times 10^{12}(\mathrm{pkm})$ was found, or an average one-way distance of $2,531 \mathrm{~km}$. This distance is $23 \%$ higher than the only other published global estimate of $2,051 \mathrm{~km}$ [2]. Significant uncertainties remain in both sets of numbers.

Finally the GTTD has been enriched with domestic tourism. The methods used for the domestic number of trips are described in Section 3.1, while the estimates for distance travelled are given in Section 3.4. Section 3.2 describes time and money budgets and Section 3.3 distance decay and power curves. Both of these sections give some new (or renewed) elements for tourism geography and are both used for the domestic travel distance estimates in Section 3.4.

\subsection{Trips as Function of GDP}

Tourism trips per capita appear to be strongly related to GDP per capita (e.g., by Bigano et al. and Peeters et al. [8,38]). We assume that this relation is valid for both international and domestic trips and is linear but with a certain maximum number of trips. Hence, domestic trips for all countries were calculated using the following equations:

$$
\tau_{T_{i}}=C_{c y}+\alpha_{c y} \cdot \overline{G D P_{c a p}}
$$

and

$$
T_{d o m_{i}}=\tau_{T_{i}} \cdot P_{i}-T_{\text {int }_{i}}
$$

The number of departures per capita $\tau_{T_{i}}$ are a maximised linear function of GDP per capita (PPP, purchase power parity) as given by Equation (1). Equation (2) gives the number of domestic tourist arrivals $T_{\text {dom }}$ for country $i$ as a function of the total departures from this country minus the (already known) international trips $T_{\text {int }_{i}}$. The coefficients are given in Table 1. GDP data generally were taken from IMAGE [41] but, in case image did not provide data, also from databases such as the CIA World Factbook $[43,44]$.

Table 1. Baseline values for the parameters determining trip generation (Peeters et al. [8]).

\begin{tabular}{cccc}
\hline Tourism market & $\boldsymbol{C}_{c \boldsymbol{v}}$ & $\boldsymbol{\alpha}_{\boldsymbol{c v}}$ & $\boldsymbol{T}_{\max }$ \\
\hline Total trips & 0.2888 & 0.00007343 & 5.0 \\
\hline
\end{tabular}

We used this method to estimate domestic tourism. The total global number of trips in the GTTD increased from $3.89 \times 10^{9}$ to $4.625 \times 10^{9}$.

Figure 2 shows a comparison of the results of our method with the results from the method by Bigano et al. [38]. Our result is just 2.6\% lower than the formerly published number of tourist trips of $4.75 \times 10^{12}$ [2]. The equation given by Bigano et al. would underestimate this total of $4.750 \times 10^{12}$ by about $17 \%$. 
Figure 2. Relations between GDP and trips per capita for the GTTD and Bigano [38].

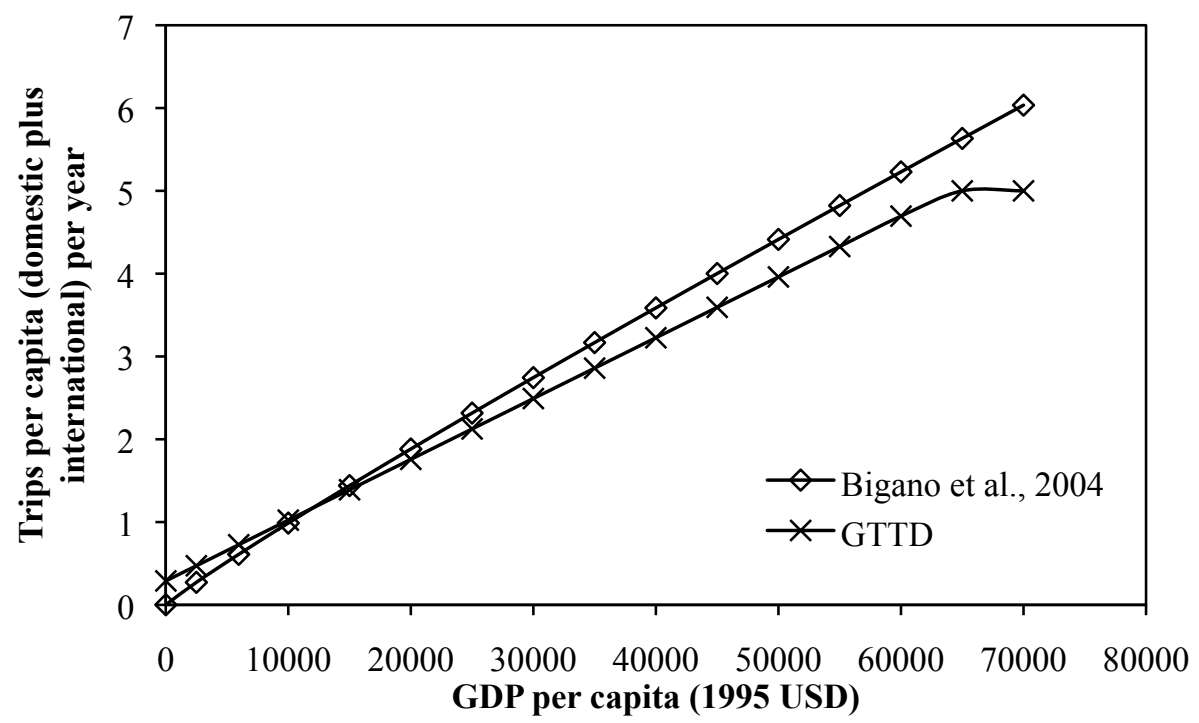

\subsection{Time and Money Budgets and Speed of Travel}

The amount people can travel is limited by time and money constraints: the travel money budget (TMB) and the travel time budget (TTB). The TMB hypotheses says that the share of income spent on transport and travel is constant when measured at the population level, while the TTB hypotheses claims that the average travel time is a constant when measured at the population level. Zahavi [45-47] and, to a lesser extent, Hägerstrand [48], were among the first to suggest these ideas, but they have been developed by others as well [49,50]. There are time budget constraints that have been successfully modeled in travel demand dynamic models [51]. The most extensive recent work on TTBs and TMBs has been published by Schafer [52,53], who also developed a global mobility model including long distance travel [54], inspiring others [55]. Furthermore, Metz [56] and Banister [57] give strong arguments for the existence of TTB and its use in transport policy, including a plea to leave the flawed transport policies paradigm that says that increasing travel speed saves time.

The constancy of the TTB is challenged as it is only found at the highest aggregation level [58]. Most of these critiques start, oddly enough, by disaggregating the population and showing differences in travel time among different population groups. This approach ignores that the 'constancy' is assumed to exist only at the population level and not for individuals of small population segments.

Kölbl and Helbing [59] relate travel patterns to the energy exerted by the traveler (the individual energy, not the energy consumption of the vehicles used) and show that this budget is a constant. It shows that all different transport modes follow the same distribution of energy used. Lin et al. [60] study the experience of travel time and find that cognitive distances are systematically underestimated at short ranges $(<150 \mathrm{~km})$ and overestimated at long ranges $(>250 \mathrm{~km})$. This result may support the idea that travel times are important as short distances of up to $150 \mathrm{~km}$ will involve trips near the average daily TTB of 60-70 minutes [52], making the trip 'feel short', while distances above $250 \mathrm{~km}$ will take much longer making their 'feel' to be rather long. 
Unfortunately, global travel time data for tourism travel are non-existent. Therefore, a relationship between travel distance and travel is suggested to impute speed to the most common travel modes, as already proposed by Miossec in the 1970s [15]. Using the Mobility Survey Netherlands (MON [61]), Figure 3 has been constructed. MON contains detailed data for 200,000 trips per year generated by 60,000 subjects. The focus of this survey is daily transport and most long international trips are missed. However, it is assumed that the way tourists use transport modes will not fundamentally differ from daily travel. The measured travel speeds were best represented (i.e., highest $\mathrm{R}^{2}$ ) by the power law model given by Equation (3), where $V$ is the speed in $\mathrm{km} / \mathrm{hr}, d$ the distance in $\mathrm{km}$ and $C_{V}$ and $b_{1}$ are the model constants estimated with PASW Statistics 18.0.

$$
V=C_{V} \cdot d^{p_{1}}
$$

For the modes private boat, ferry, sea- and river-cruise, and local public transport (bus, tram), we assumed a constant speed because the number of trips in MON was too low or the scatter was too large to accurately calculate the speed. For cycling and walking we assume that these also have a constant speed independent of distance. Figure 3 shows the result.

Figure 3. Transport speeds per transport mode as modeled from the MON database [61]. Power curve fit: (a) logarithmic plot for all distances; (b) linear plot for 0-1500 km.

(a)
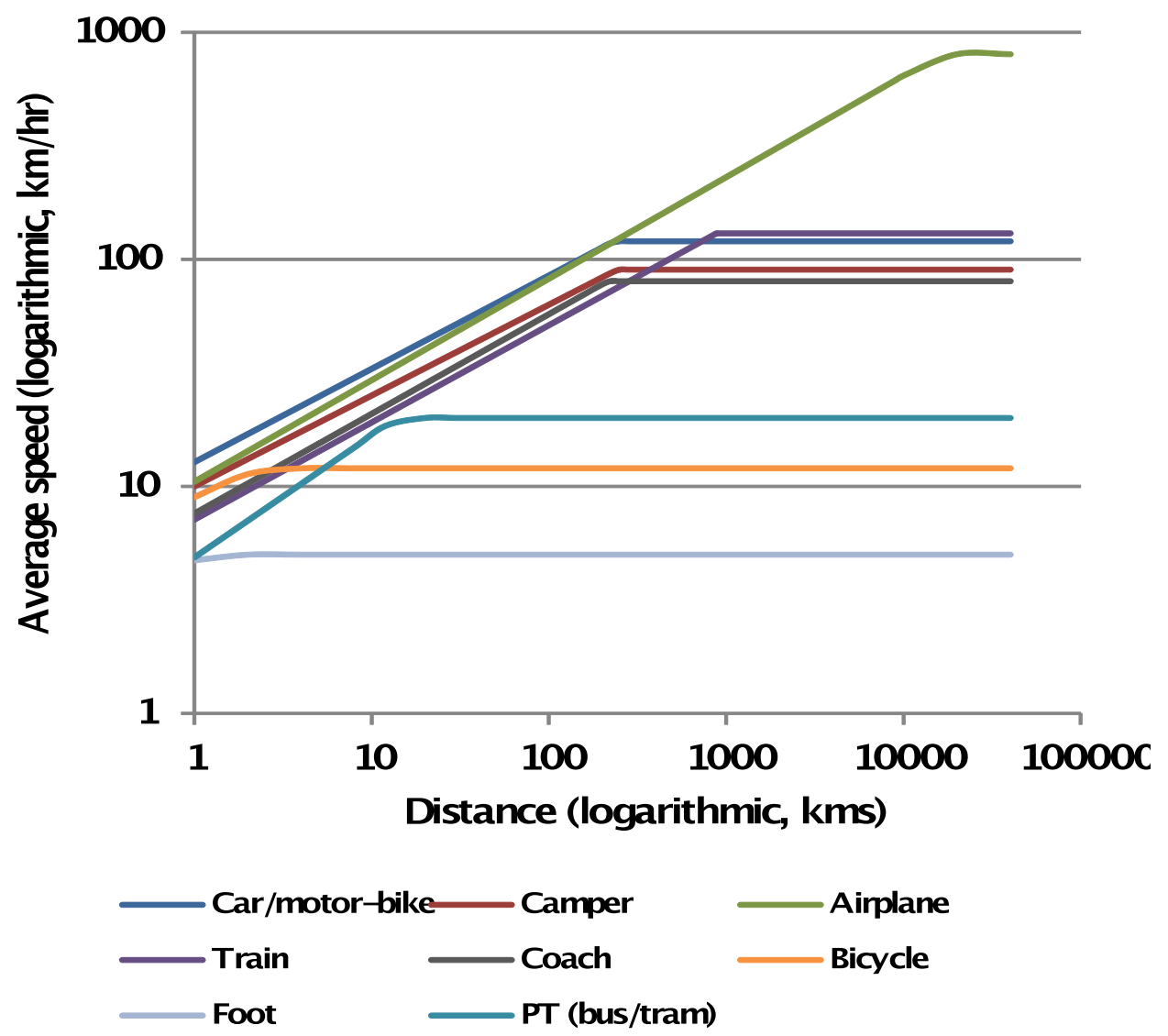
Figure 3. Cont.

(b)
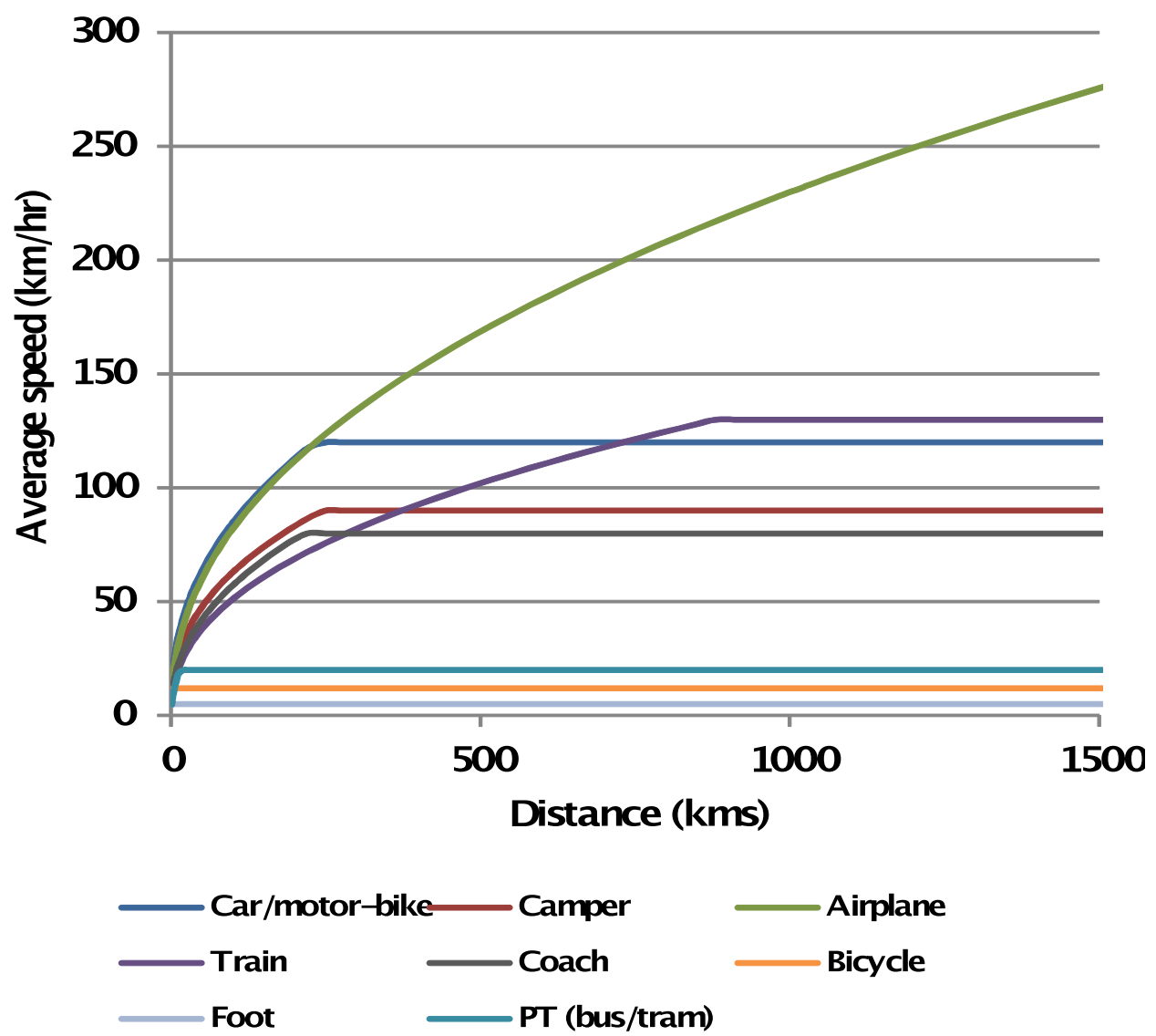

The train data are based on conventional speed trains (less than $180 \mathrm{~km} / \mathrm{hr}$ maximum speed). MON does not include high speed rail data, but we expect these will show comparable or better average speeds on trips up to $1,500 \mathrm{~km}$.

\subsection{Distance Decay and Power Curves}

Early attempts to develop tourism geography $[15,16,62]$ related transport system qualities such as cost, distance and speed to travel patterns in a conceptual manner, were inspired by gravity models. These models assume transport flows to be proportional to the 'masses' of origin and destination and inversely proportional to the distance between them [23,63-66], where distance is defined as a mix of physical distance, cost, travel time and discomfort. This idea is closely related to the 'distance decay' [62,64,67-69] theory that assumes the frequency of trips to be inversely proportional to physical distance. Distance decay has even been formulated as the 'first law of geography' (p. 236 in Tobler [68]), which says that "everything is related to everything else, but near things are more related than distant things". Only a few authors have published distance decay for tourism [62,70-74].

For global travel, McKercher [71] finds a surprisingly good fit for 2002 international arrivals, with just a small secondary maximum for the distance class between 5,001 and 6,000 km. For 2005, our GTTD shows the same maximum at $5,500 \mathrm{~km}$ and two more at 9,500 km and at $16,500 \mathrm{~km}$ (see Figure 4). The maximum at $5,500 \mathrm{~km}$ is mainly caused by transatlantic travel (63\% between Europe and North America), while the maximum at 16,500 km shows most (79\%) traffic between Oceania with either Europe or the USA. The 9,500 km maximum has no specific origin. 
Figure 4. Distance decay and power curve for international arrivals in 2005 (data per nation; source: GTTD).

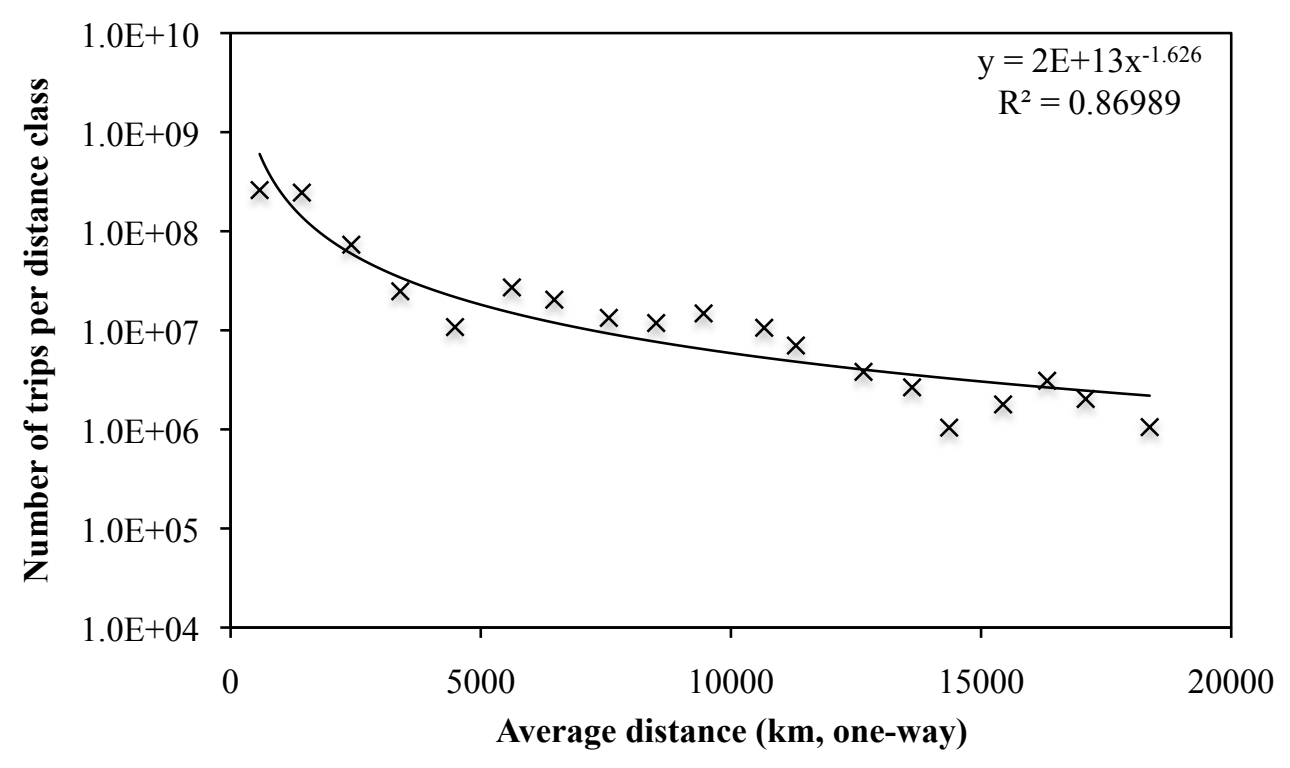

Many phenomena in nature and society follow a bell shaped probability curve (e.g., the weight distribution of people, which has a clear average and reduced probability the farther away from this average). However, there is also a class of phenomena that follow a much different probability curve that has a very high probability at one end of the range of occurrences and very low at the other end. These power curve probabilities are often suggested for varying physical, natural, economic and social phenomena [75-81]. Examples of phenomena following a power distribution are earthquakes [75], the number of species in general [79], the use of words [77] and the distribution of wealth [82]. Generally, power curves do not cover the whole dataset but only from a certain minimum cut-off value of the phenomenon. Newman et al. [79] mention seven mechanisms in phenomena that may generate power curves in nature of which at least one, the random walk, may be applicable to tourism travel. The random walk literally means that the amount of time before a subject that makes random moves returns to his original position has a power probability (very frequent short times and very infrequent long times). These random walks, also called 'Lévy Flights' [83,84] have been shown to occur in human travel $[85,86]$. They are also shown $[87,88]$ and disputed [89] for foraging animals. Section 4.1 highlights Lévy Flights for Dutch travel and Section 4.2 for global travel.

\subsection{Country Size and Domestic Tourism Travel Distances}

The average distance domestic tourists travel will mainly be a function of the size of the country and to some extent the quality of the infrastructure. Based on data from the MuSTT study [90] we drafted a relation between the average domestic distance and the size (the area of land surface in $\mathrm{km}^{2}$ ) and fitted a curve to these data (see also Figure 5):

$$
\bar{d}_{i}=\varepsilon_{q} \cdot 1.6792 \cdot A_{i}^{0.4387}
$$

where $d_{i}$ is the average domestic one-way distance in km and $A_{i}$ is the country's land area in $\mathrm{km}^{2}$. The factor $\varepsilon_{q}$ is an indicator of the quality of the road network, which we consider to be of a better quality in 
developed countries, enabling higher travel speeds. To be consistent with former work, we set $\varepsilon_{q}$ to 1.0 for developed countries, designated OECD90 in the IMAGE models [41] and 0.8 for all other countries.

Figure 5. Relation between land area $\left(\mathrm{km}^{2}\right)$ and average one-way distance for domestic tourism (source: [90]).

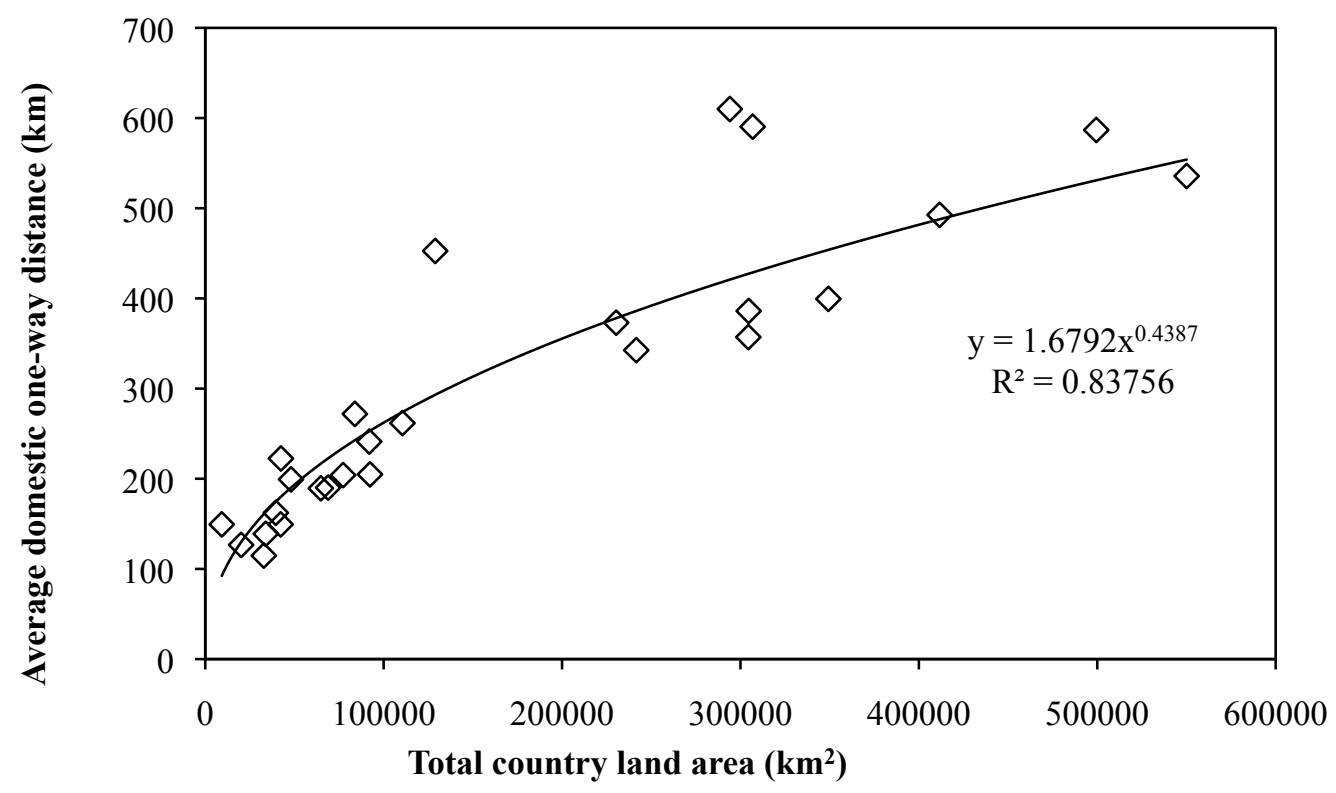

With the method described above, we know the number of domestic trips and the average distance travelled at the scale of nations. This information increases the total distance travelled in the world from $3.72 \times 10^{12}$ billion pkm to $11.36 \times 10^{12}$ billion. The new distance decay results for global tourism are given in Figure 6.

Figure 6. Distance decay and power curve for global tourism (domestic and international; data per nation; source: GTTD).

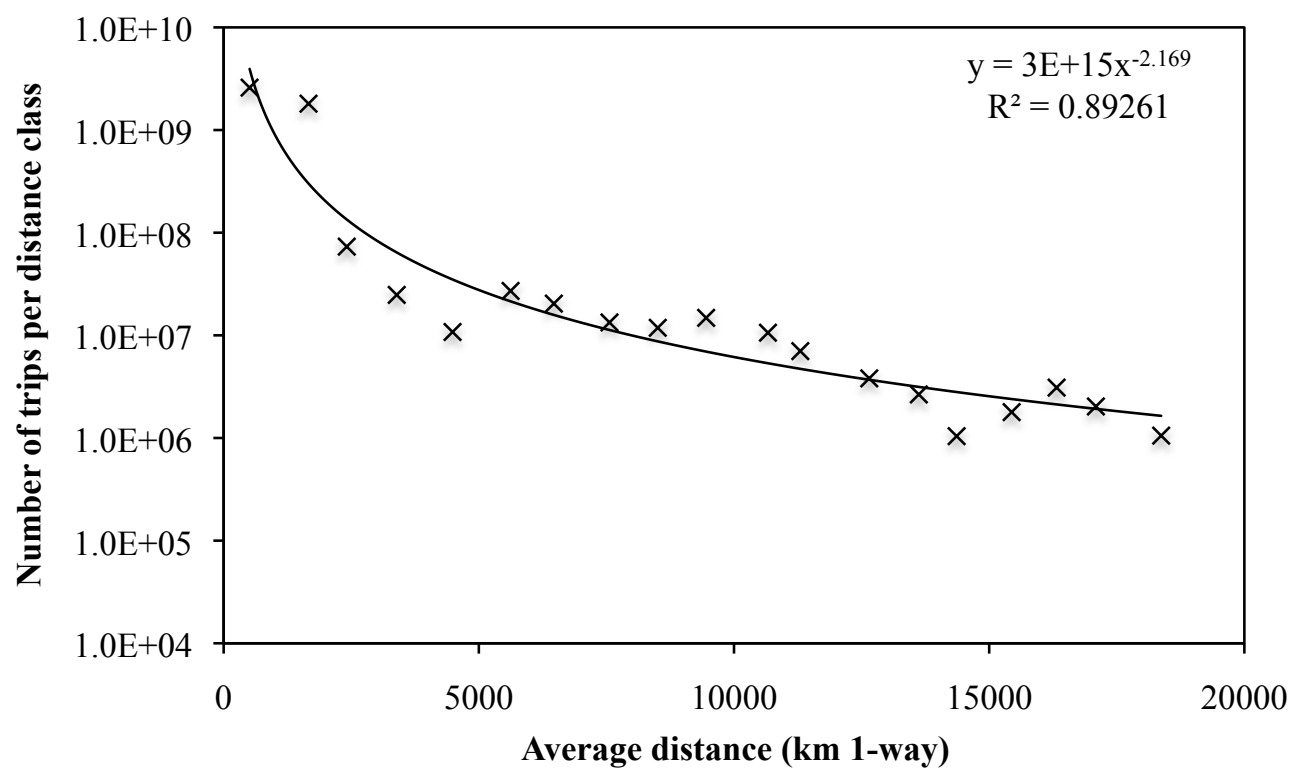


All domestic trips ended up in one of the first two distance classes. This distorts the figure, as, domestic trips will also be distributed in the same way as international trips, thus with most trips in the lower distance classes and fewer trips for medium to, in the largest countries, even for long haul trips. In the GTTD, the 15 largest domestic flows $(0.1 \%$ of all data points in GTTD) represent $61 \%$ of all trips. Therefore, we have redistributed the 13 largest (all domestic) data points plus two additional large points that are in geographically large countries (Australia and Canada). These 15 data points represent $60.3 \%$ of all trips in the GTTD. For this analysis we assumed a power curve distribution for one-way distance classes with averages of 200,400 and so forth up till 7,000 km. The power curve is as follows:

$$
n_{T}=C \cdot d^{-\mu}
$$

where $\mathrm{n}_{\mathrm{T}}$ is the number of tourists, $d$ is the average distance of a distance class, $C$ is a constant and $\mu$ is the power coefficient. The minimum value $d_{\min }$ is defined by the following relation between $C$ and this minimum value [78]:

$$
C=(\mu-1) \cdot d_{\min }^{\mu-1}
$$

We used Equation (6) and the 'known' average value and maximum distance (measured using the Google Maps distance tool) to find a value for $\mu$ using Excel's Solve add-in and fitting the trip numbers per distance class to the total known domestic trips. Table 2 shows the results. Note that the power law exponents are relatively low with the exception of France. Further research is needed on this issue.

Table 2. Overview of the power law constants for the 15 countries with the largest domestic tourism demand.

\begin{tabular}{lcccc}
\hline \multirow{2}{*}{ Country } & $\boldsymbol{\mu}$ & \multicolumn{2}{c}{ Distance (km, one-way distance) } \\
\cline { 3 - 5 } & & Maximum & Minimum & Average \\
\hline Australia & 1.123 & 3,600 & 800 & 1,757 \\
Brazil & 1.303 & 4,300 & 400 & 1,286 \\
Canada & 1.155 & 5,200 & 600 & 1,908 \\
China & 1.394 & 5,000 & 400 & 1,342 \\
France & 2.698 & 1,200 & 400 & 536 \\
Germany & 1.260 & 1,000 & 200 & 399 \\
India & 1.235 & 3,500 & 200 & 813 \\
Indonesia & 1.682 & 5,300 & 200 & 654 \\
Italy & 1.781 & 1,200 & 400 & 610 \\
Japan & 1.731 & 2,500 & 200 & 469 \\
Mexico & 1.408 & 3,300 & 200 & 679 \\
Pakistan & 1.612 & 1,800 & 200 & 450 \\
Russia & 1.269 & 6,000 & 600 & 1,971 \\
United Kingdom & 1.884 & 1,300 & 200 & 343 \\
United States & 1.175 & 7,000 & 400 & 1,902 \\
\hline
\end{tabular}


Clearly the 'power curve' fit improved (see Figure 7), although it appears to be following two separate power curves: one in the domestic domain of distances and the other in the medium to long haul international domain. Without better national tourism data it remains unclear if the imputed domestic distance class distribution is realistic.

Figure 7. Distance decay for global domestic and international tourism flows from the final GTTD with large domestic data points redistributed (smoothed).

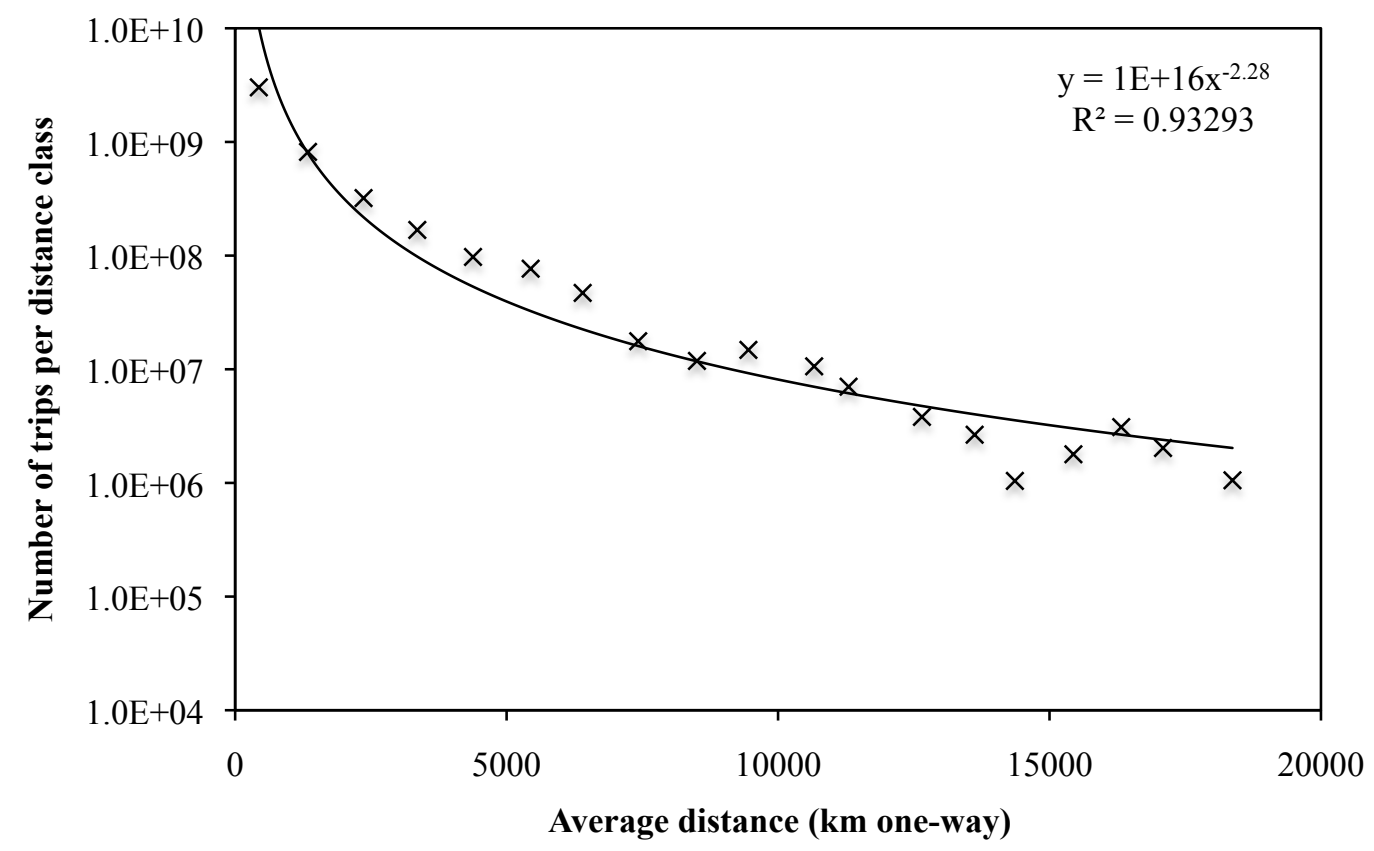

\section{Tourism Geographies: Towards Sustainable Development}

In Section 4.1 the Dutch case will be introduced, as The Netherlands seems the only country with a sufficiently detailed database for Dutch outbound tourism (excluding business). This database includes information about the time and duration of the trip, transport modes, spending, and (imputed) distances. This information is needed to give some statistical evidence for the ideas presented in Section 3. In Section 4.2 we return to the global level of analysis. Some of the findings from the Dutch case are applied globally, and the flaws in contemporary global tourism geography, which is based on international travel, are discussed.

\subsection{Dutch Holiday Travel}

Dutch holidaymakers travel all over the world. Figure 8 is based on data from the Dutch Continuous Holiday Survey (CVO [91]) and shows all 104 of the largest international flows. The CVO survey distinguishes 299 destinations with a high resolution at short distances (e.g., at the province level in The Netherlands, Belgium, UK, Germany and France). Travel distances were calculated based on the great circle distances to these destinations [42]. These distances were increased by a certain factor per transport mode to accommodate for detours (see the Travelling Large report [92] for further details about the methods used). Furthermore, travel times were generated that are based on average travel speeds as a function of distance (see Section 3.2). 
Figure 8. Dutch holiday makers 104 largest international flows for 2009. Background shading gives the total distance (pkm) travelled to the destination country, while the wedge width is a measure of the number of trips.

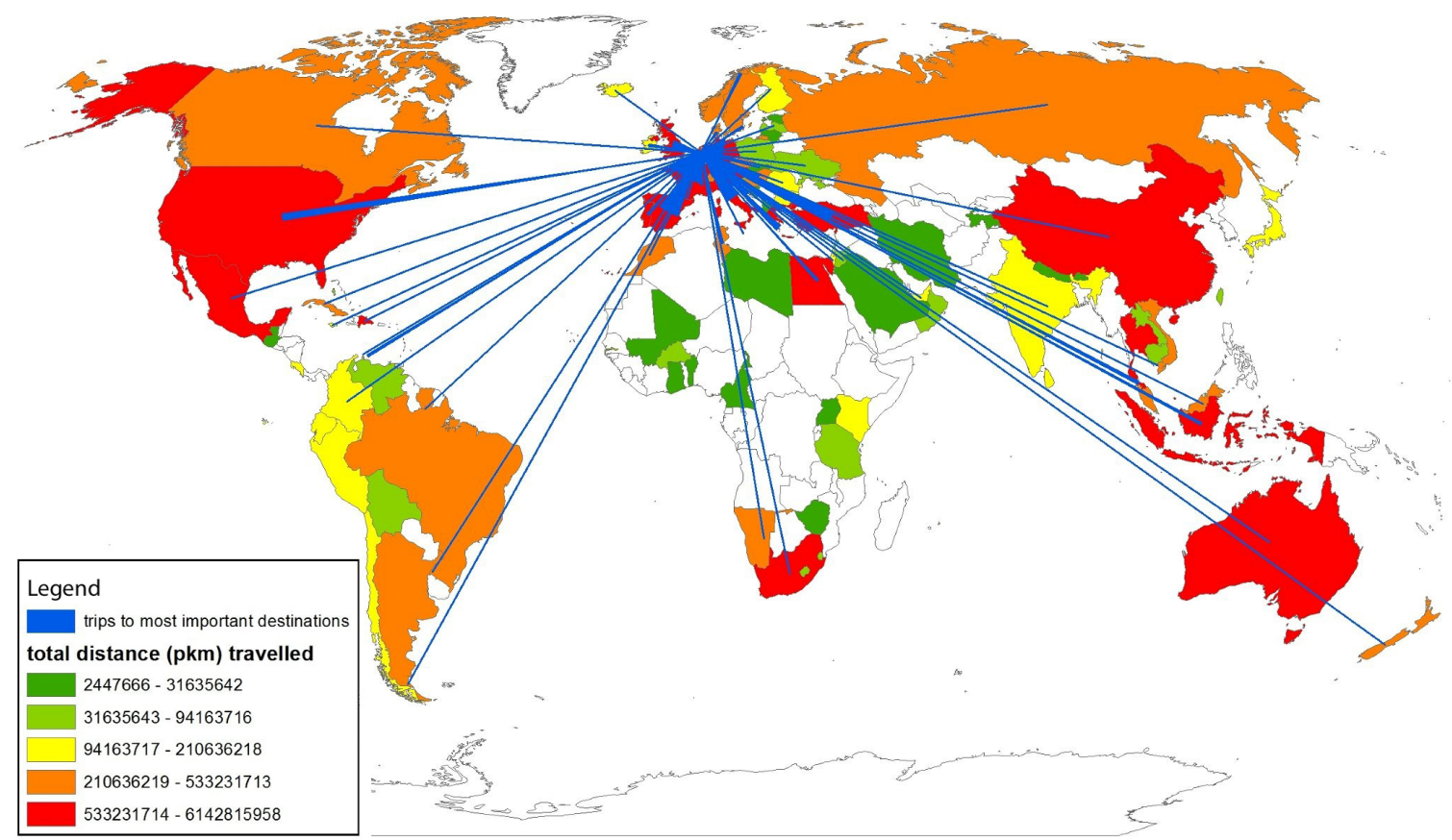

We tested the distribution frequency of trips per distance class (in classes of 1,000 km one-way distance from 0 up to $20,000 \mathrm{~km}$ ) and found a power law best represented (largest $\mathrm{R}^{2}$, though still just 0.71) and a coefficient of 2.06. Most of the scatter appears in the tail of the distribution, where numbers per class are low (see Figure 9(a)). This result gives some support for the power law relation of tourism travel by Dutch holidaymakers, but the result is much weaker than for the global case as shown in Figure 7.

When a TTB is a valid proposition, it might be that travel time is the quantity measured by the human brain, acting as a reference to humans' travel decisions. In that case, the power law for travel time should result in a better fit than for travel distance. Figure 9(b) shows that total travel time has a much better power curve relation than distance (exponent of 2.685 and $\mathrm{R}^{2}=0.94$ ). The idea that travel time is the main parameter in travel decisions has support in the literature concerning the TTB [45,49,50,56,57,93]. Kölbl et al. [59] tried to find a physical mechanism for TTB and found it in canonical energy use during travel. The idea that travel time might be related to daily energy use has been convincingly found for animals, as exemplified by the airborne time and energy use of kestrels [94-96]. For example, it appears that kestrels have a rather constant activity pattern with approximately 1 hour daily of flight/hunting, except during breeding season when this time increases to approximately 4 hours. However, 4 hours is still far short of the maximum activity time the birds physically could achieve. When the number of chicks in the nest is manipulated, those kestrels confronted with more chicks than they chose to raise showed a much lower survival rate the next season. This reduction might be a strong evolutionary mechanism that creates daily energy constancy of which daily movement (flight) is a derivative, giving support to Kölbl et al. [59]. 
Figure 9. Trip distribution for distance travelled (a) and travel time (b) by Dutch holidaymakers (source: CVO [91]).

(a)

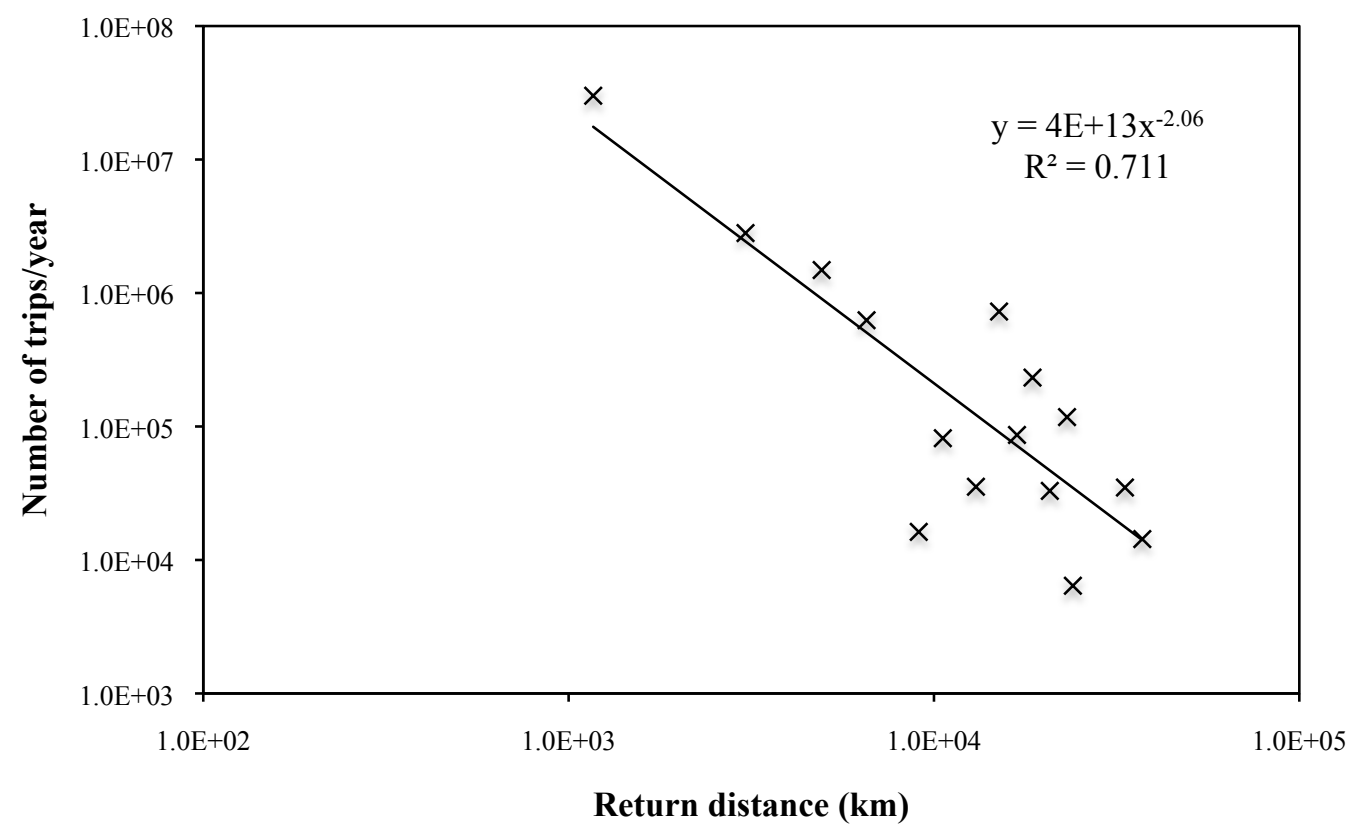

(b)

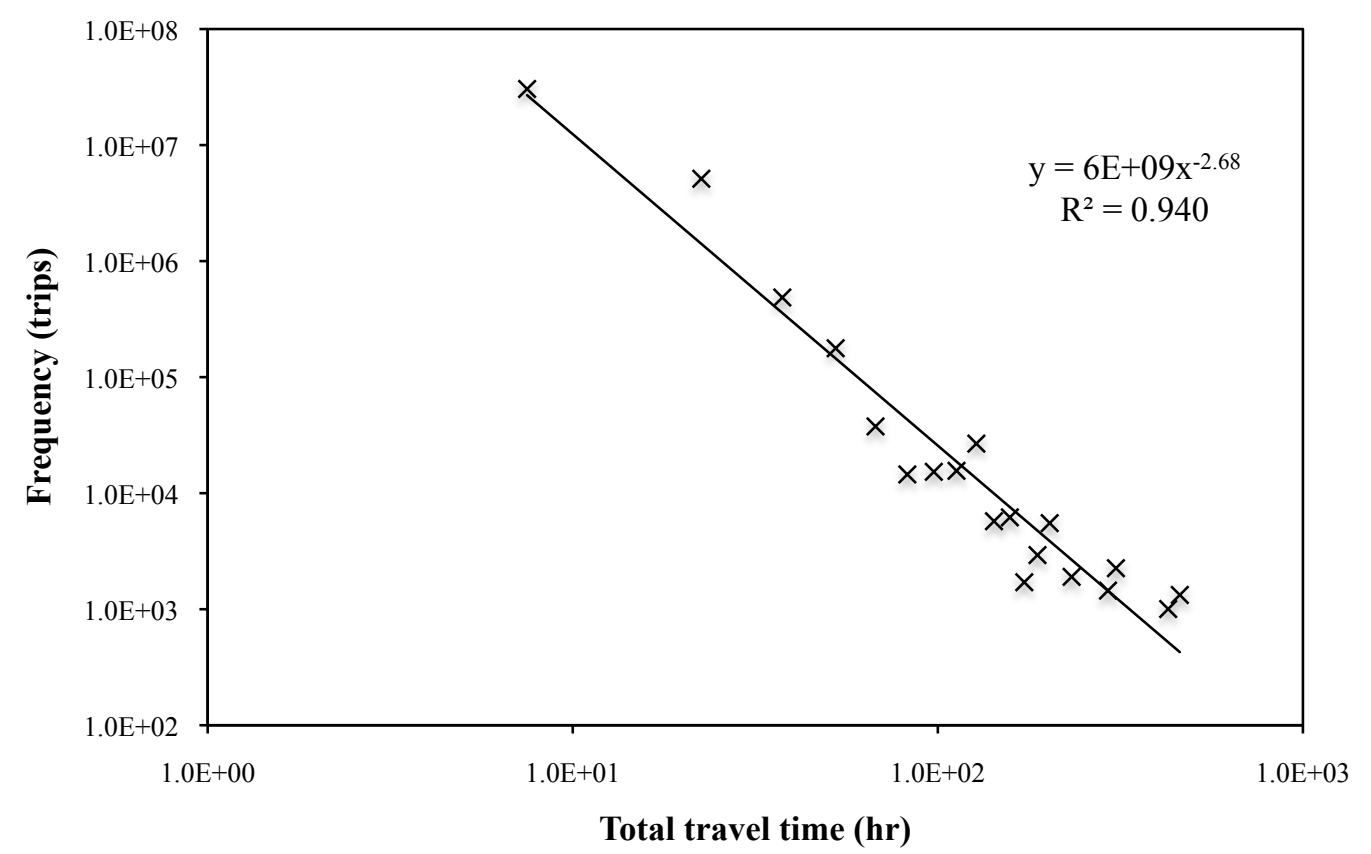

Based on calculations of the carbon footprint of Dutch holidaymakers between 2005 and 2010, we found an increase in carbon emissions from holidaymakers, except for a dip in the economic crisis year 2009. Both the growth and 'dip' are associated with the share of air travel and the average distance travelled; the number of trips was almost constant, giving support to the idea that travel time is more or less a constant. Thus, distance is the dependent and travel speed the independent variable. Both of these variables are strongly related in 2009 for length of stay, cost per day and travel speed (Pearson correlation in bivariate of distance is highest for average speed (0.818), followed by cost per day (0.464) and length of stay (0.402). The carbon footprint calculations include technological energy efficiency improvements calculated for air transport based on Peeters and Middel [97] and measured by the Dutch Statistical Office (CBS) for other transport modes in the Netherlands [98]. As speed and 
concomitant distance growth is a strong driver for carbon footprint growth, it is necessary to explore what impacts distance restrictions might have on global tourism.

\subsection{Global Tourism Flows}

Figure 10 shows a geography based map on nations for the 168 most important relations of the 12,000 plus relations in the GTTD. These flows represent $90 \%$ of all international trips. Clearly, international tourism is not evenly distributed over the world, and there is a strong bias to the more developed parts of the world. Figure 10 also shows the 'fatter' wedges are those at shorter distances between large countries (such as the USA and its neighbors).

Figure 10. The main international tourist flows in 2005 and income per capita (for 2003 in 2000 USD; based on GTTD).

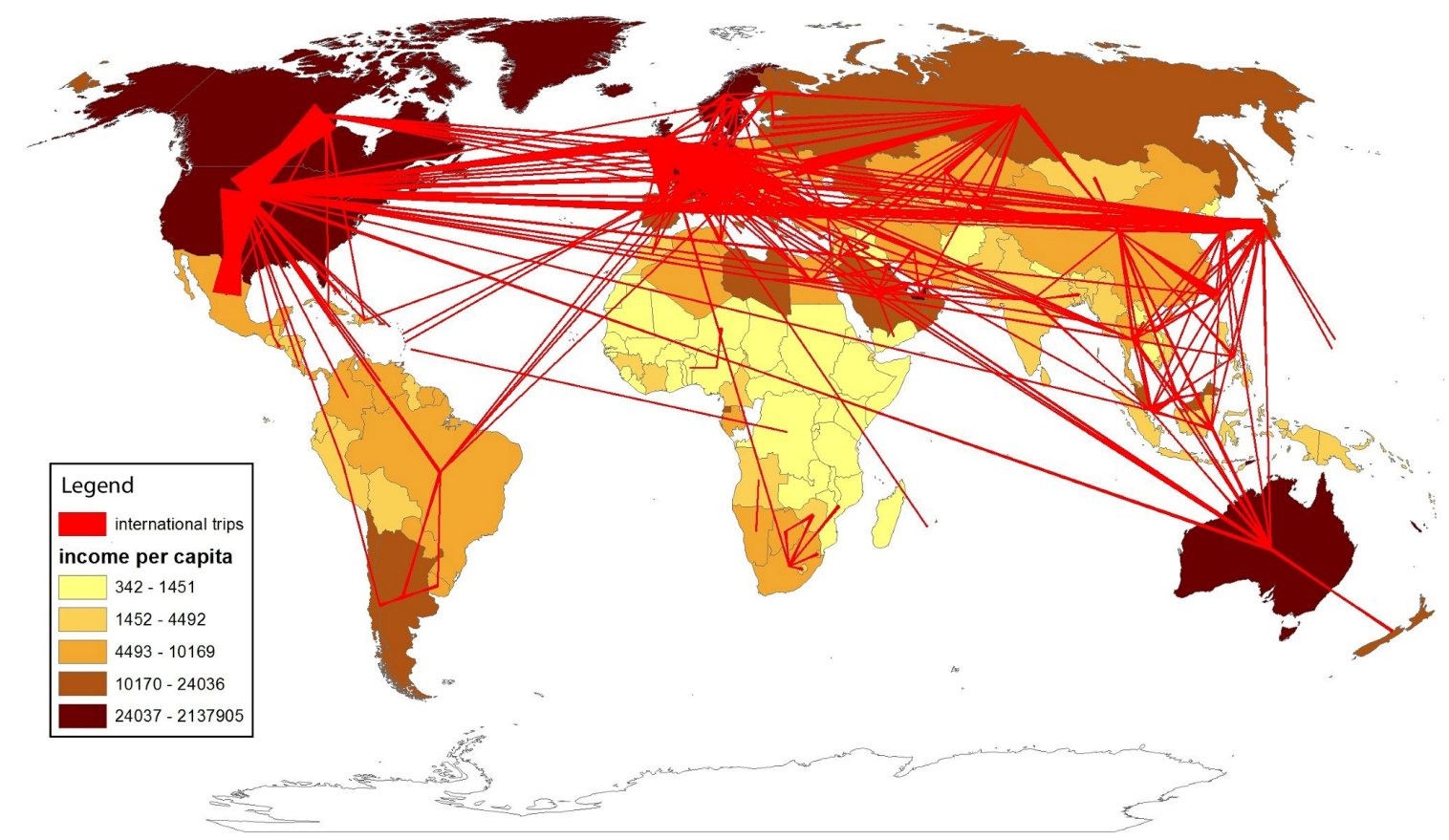

Many developing countries in Africa, Asia and Latin America do not show any international arrivals because their international tourism flows do not belong to the 168 largest flows we selected. This map also reinforces the perception that Europe is the most important (international) tourism destination.

However, these impressions are incorrect due to some serious caveats underlying the use of only international flows, as outlined in Section 3. First, international flows represent only $17 \%$ of all tourism trips as they ignore the 3.89 billion domestic trips (see Section 3.1). Second, international flows are based on flows between very uneven geographic entities, nation states, which are the main cause of the high density of flows in Europe and relatively small flows in North America and Asia. Therefore, we introduced a geographical division of the world that is based on the IPCC scenarios and gives a fairly equal mix of global population, economy and surface area [41].

Figure 11 uses the GTTD to show all of the relations between 17 out of the 18 world regions (Antarctica has no data) for both international and domestic tourism. This map looks rather different from the one in Figure 10. The short but thick intra-regional flows now dominate over the numerous 
thin inter-regional flows. Also, tourism is now more attached to the richer parts of the world, and the 'special' position of Europe has almost been lost.

Figure 11. Global map of all flows between and within the IMAGE regions in 2005. The flows are measured in arrivals and include international and domestic tourists (income per capita for 2003 in 2000 USD; source GTTD).

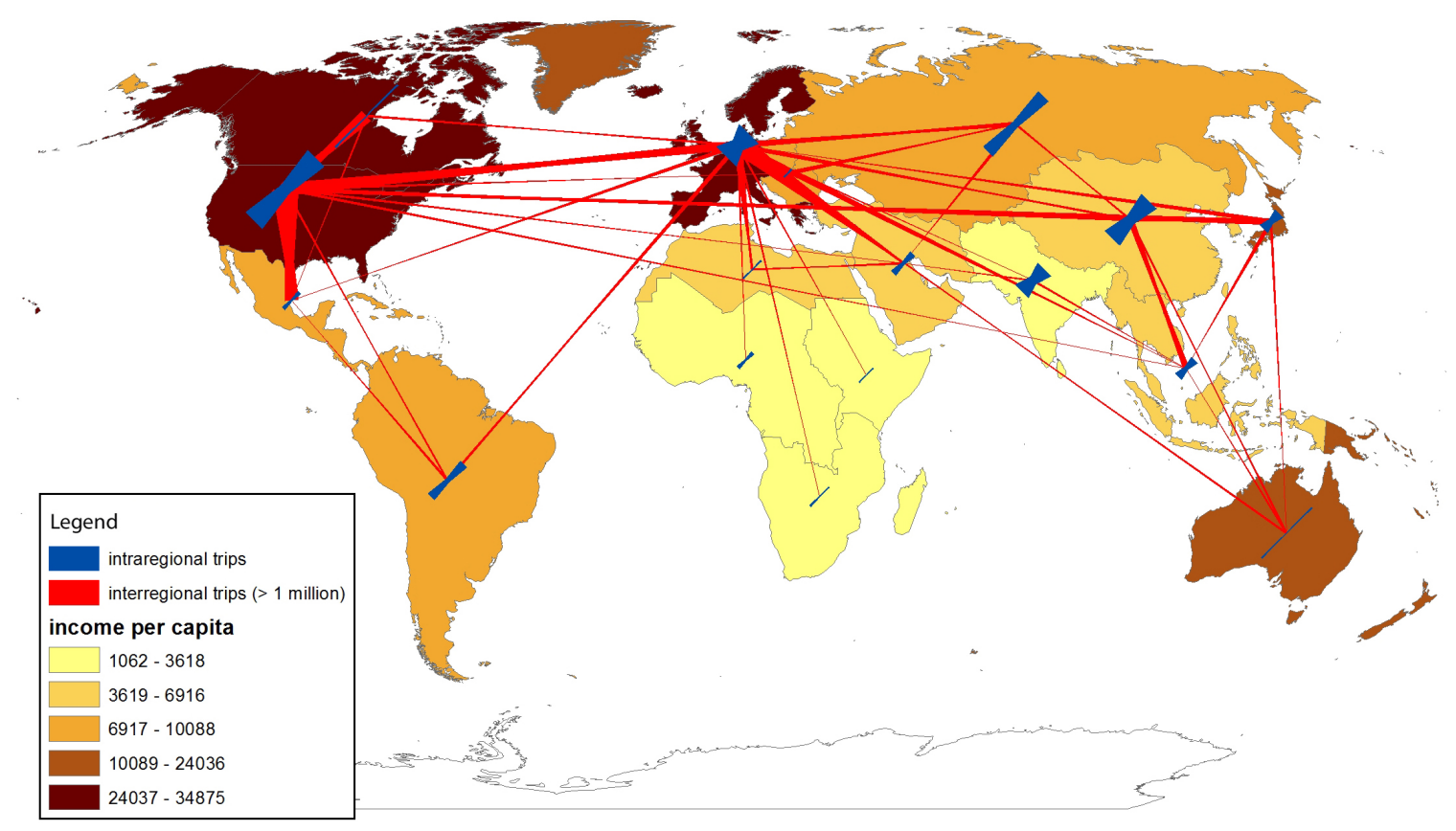

\subsection{Mitigating Climate Change by Reducing Tourism Transport}

As shown in the literature, a large gap exists between emission reduction goals and mitigation options, such as improved technology, energy efficiency and switching from air and car transport to low-carbon transport modes (e.g., coach and train) [1,2,7,99]. The main, but not only, problem is that the growth in aviation volume outpaces the benefits of technological efficiency improvements [100-102]. One way to achieve substantial absolute emission reductions often suggested is to switch aviation to biofuels [103-105]. However, there are doubts about the life cycle reductions to be achieved with alternative fuels and problems such as space use, conflicts with food production, and potential loss of biodiversity [106]. It also appears that initially promising biofuels as Jatropha seeds [103], depend greatly on where the seeds are planted [107] and may have serious environmental, social and economic problems associated with them [108-112]. Some researchers recommend using caution when suggesting biofuels such as Jatropha will contribute to large scale greenhouse gas emission reductions $[111,113]$. In addition, technological solutions have, historically, often not lived up to their expectations [7,114,115].

These problems mean that another solution appears inevitable: decoupling transport volume growth from tourism growth, or, in other words, reducing the average distance people travel per tourist day [116,117]. Figure 12 shows Lorenz curves based on the GTTD for the relation between the share of trips and the share of total distance travelled, with trips ordered from short to long distances. The point labels show the 'cut-off distance' for the case of the fully developed GTTD, including the 15 largest domestic flows redistributed over different distance classes. For example, the ' $2000 \mathrm{~km}$ ' point 
shows that $83 \%$ of all trips are shorter, while these trips cover $42.5 \%$ of all distances travelled. Thus, if by some measure people were not able to travel farther than $2000 \mathrm{~km}$, this would reduce tourism trips by $17 \%$ while reducing total distances travelled by $57.5 \%$.

Figure 12. Some Lorenz curves for trips and distance development; trips sorted from low to high distance; labels refer to the one-way distance associated with the share of trips and the total distance of that data point (source: GTTD).

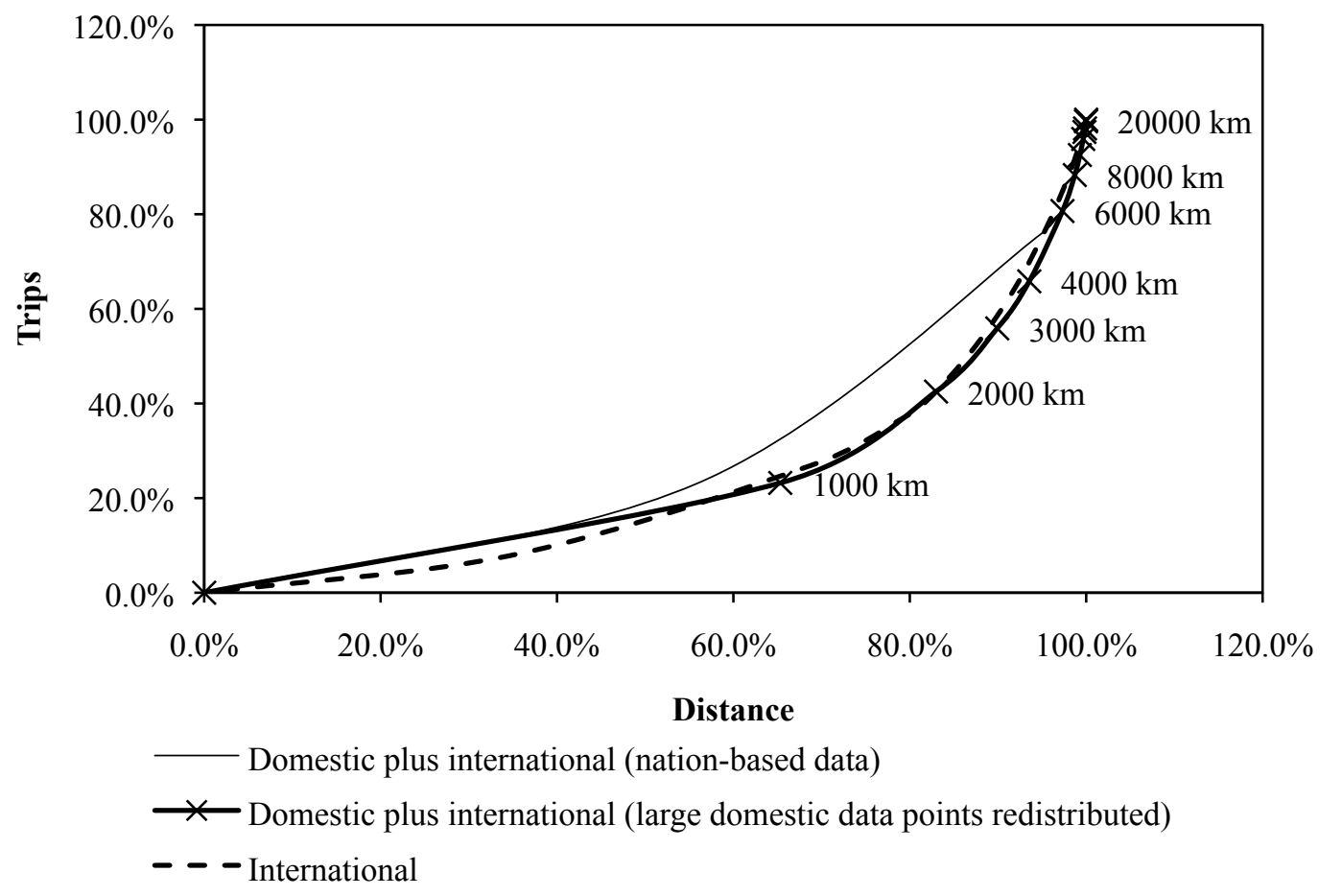

Reducing the number of medium and long haul trips may hypothetically be achieved in different ways: high taxes on air travel, issuing a system of personal travel budgets or capacity restrictions within the (air) transport sector. The question is whether tourists will simply cancel their long haul trips when confronted with such measures and spend their money outside the tourism industry or if they will choose a closer destination. Currently, no research can give a conclusive answer to this question, but the reaction to the recent economic crisis perhaps gives an indication. The OECD concludes that in times of economic uncertainty people tend to save on international and air travel and shift towards domestic and car travel [118]. This same effect has been found in a time series of travel by Dutch holidaymakers. The crisis in 2009 caused a reduction of the holidaymakers' carbon footprint by $3.8 \%$, while in 2010 , in the middle of an on-going crisis, the emissions increased again by $2.6 \%$. Therefore, a model has been created based on the GTTD that first calculates the number of departures from each country that would cover a larger distance than the cut-off distance and then redistributes these trips proportionally over all of the remaining destinations for each country. Thus, the total number of trips remains constant while all of the trips above the cut-off distance are redistributed. 
Figure 13. Impacts of distance cut-off on global tourism flows. Income per capita for 2003 in 2000 USD. (a) Unrestricted tourism flows, inter- and intraregional. Trips: $4.625 \times 10^{9}$, Distance: $11.360 \times 10^{12} \mathrm{pkm}$; (b) Cut-off distance $6000 \mathrm{~km}$, inter-and intraregional. Trips: $4.625 \times 10^{9}$, Distance: $9.482 \times 10^{12} \mathrm{pkm}$, Distance reduction: $16.5 \%$; (c) Cut-off distance $3000 \mathrm{~km}$, inter-and intraregional. Trips: $4.625 \times 10^{9}$, Distance: $7.286 \times 10^{12} \mathrm{pkm}$, Distance reduction: $35.9 \%$; (d) Cut-off distance $1500 \mathrm{~km}$, inter-and intraregional. Trips: $4.625 \times 10^{9}$, Distance: $5.370 \times 10^{12} \mathrm{pkm}$, Distance reduction: $52.7 \%$.

(a)

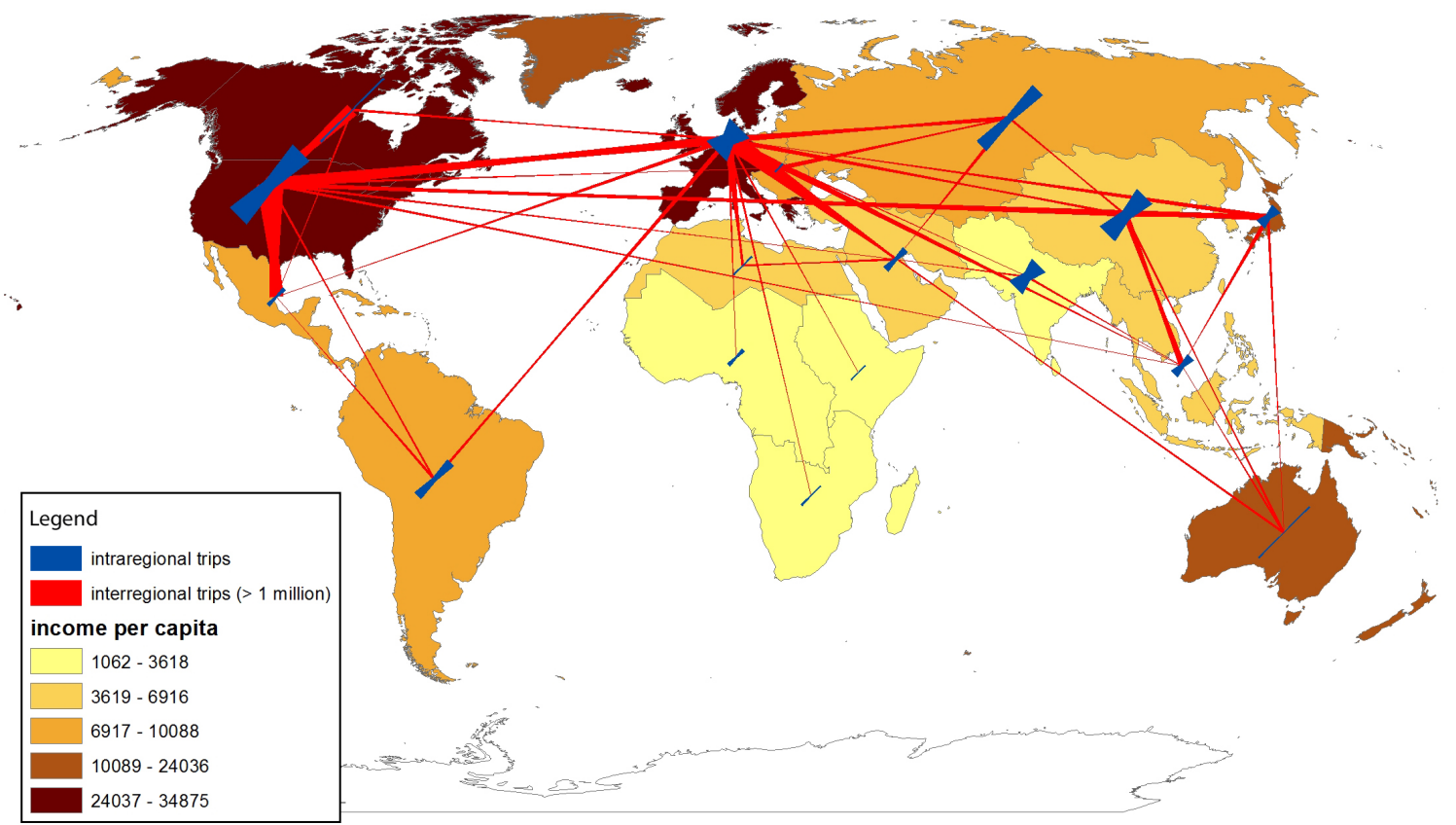

(b)

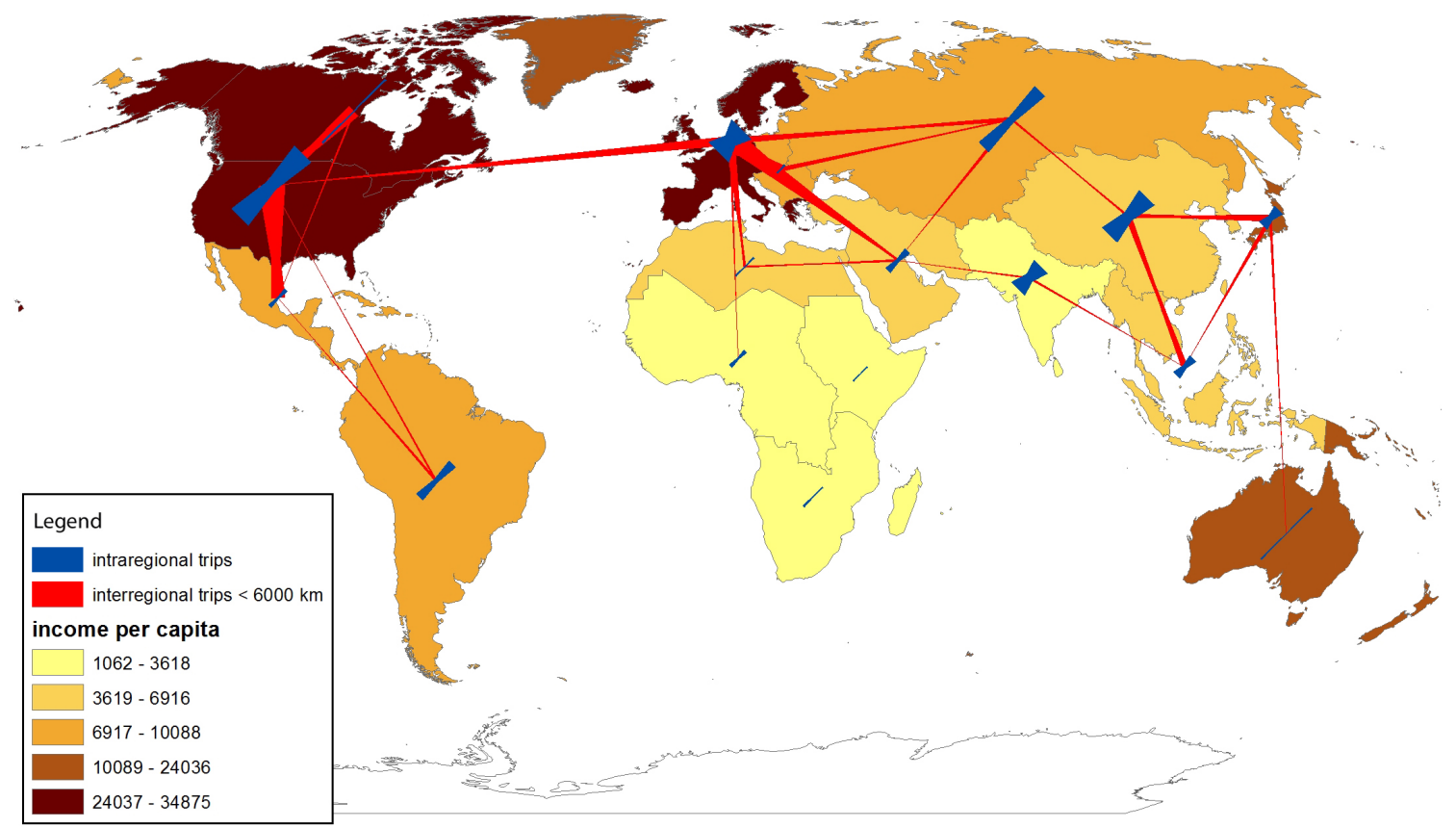


Figure 13. Cont.

(c)

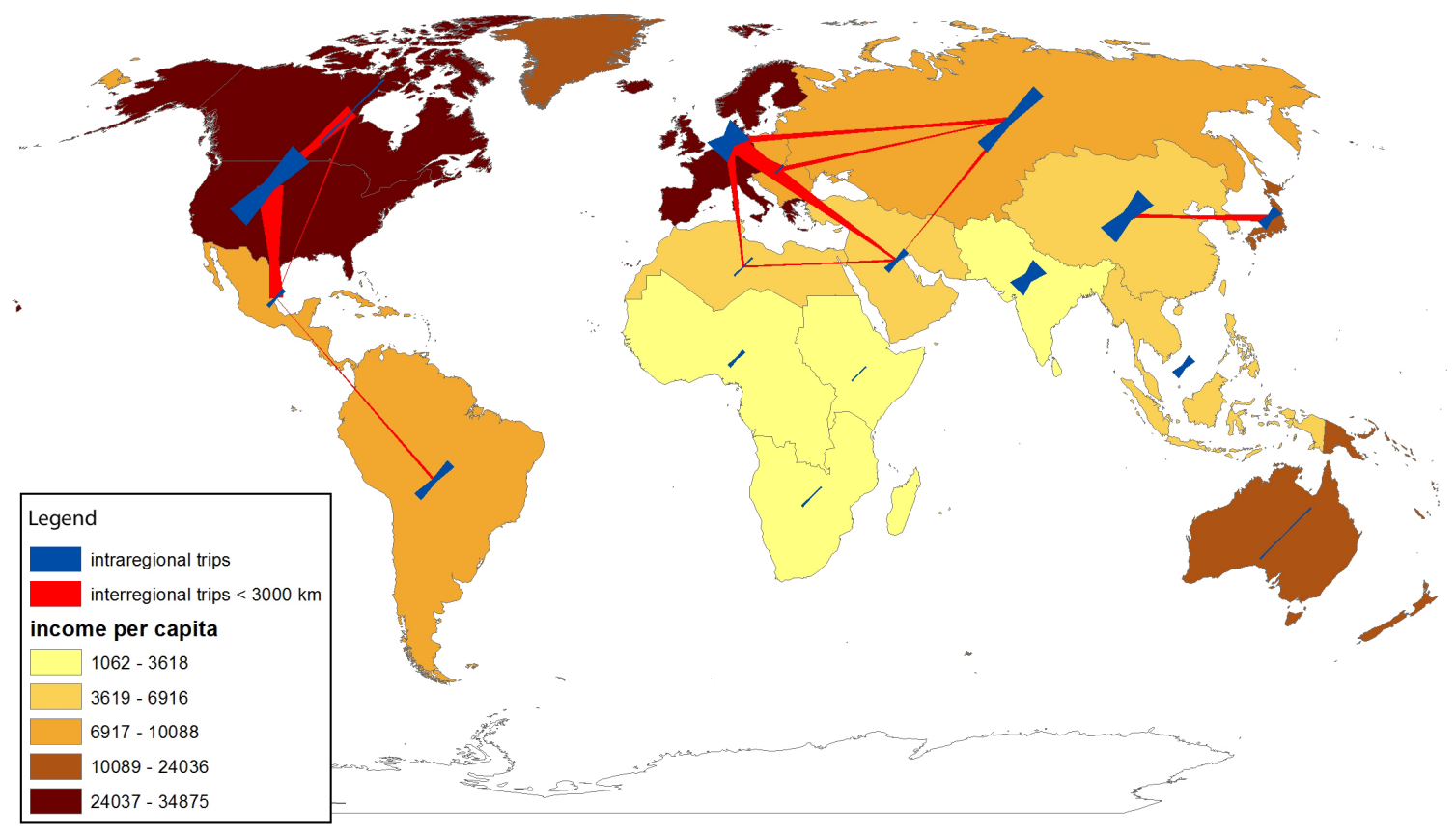

(d)

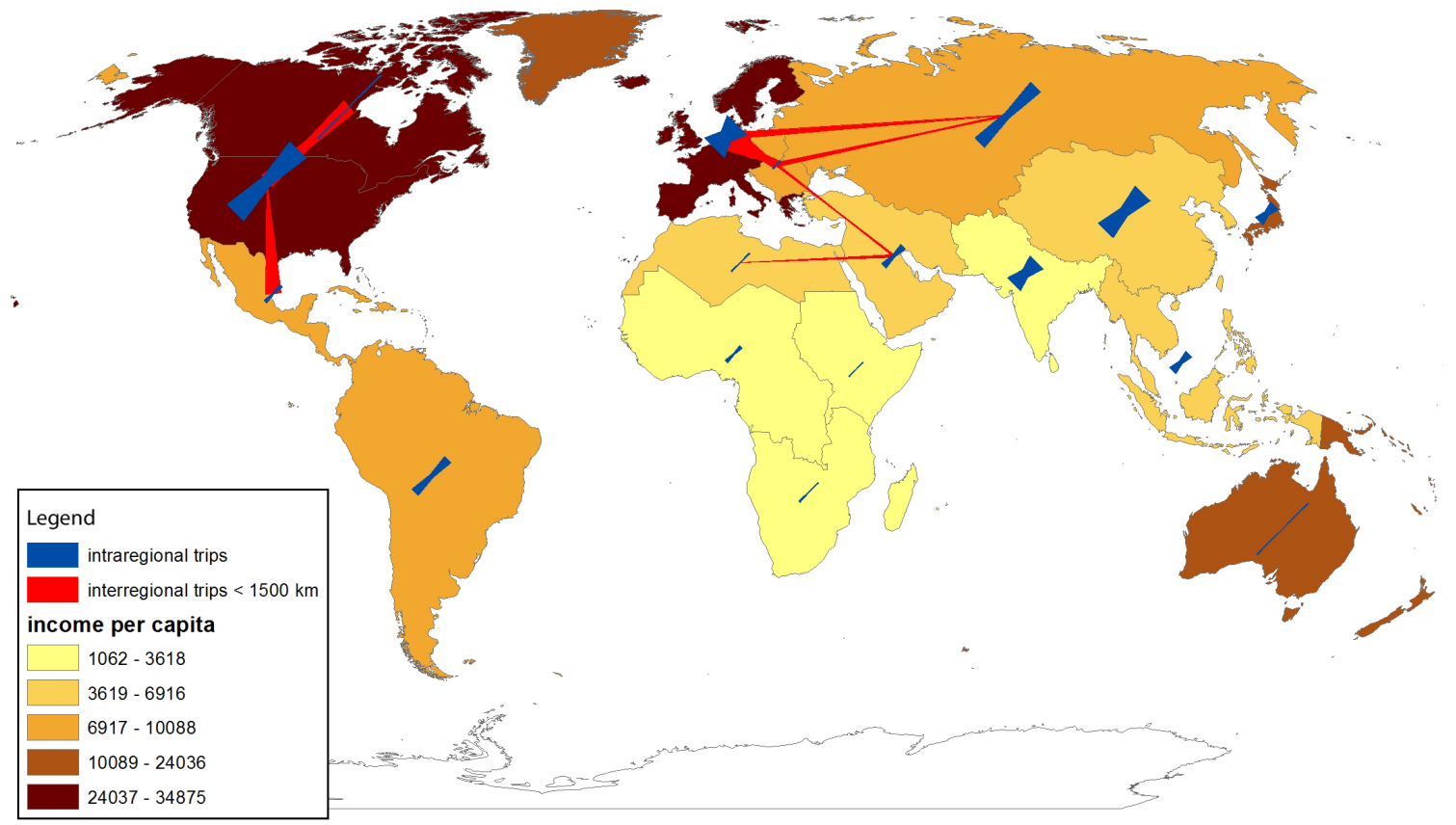

Figure 13 shows the results for cut-off distances of 6,000, 3,000 and 1,500 km (one-way) distance, in terms of distance reductions of the travel pattern on global maps. Distance reductions vary between $16.5 \%$ for a $6,000 \mathrm{~km}$ cut-off distance to and $52.7 \%$ for $1,500 \mathrm{~km}$ one-way cut-off distance. These cut-offs produce is substantial reductions of distances. However, the reduction of emissions may even be stronger as average emissions are some $20 \%$ lower for return distances below 2,500 km (see Figure 14). More importantly, the opportunities for emission reductions also improve greatly for the same short haul trips as the lowest attainable emission factors drop by $50-60 \%$ compared to return distances above 5,000 km. To achieve such larger reductions, strong transport mode shifts will be needed. 
Figure 14. Average emission factors and standard deviation based scatter (source: [119]).

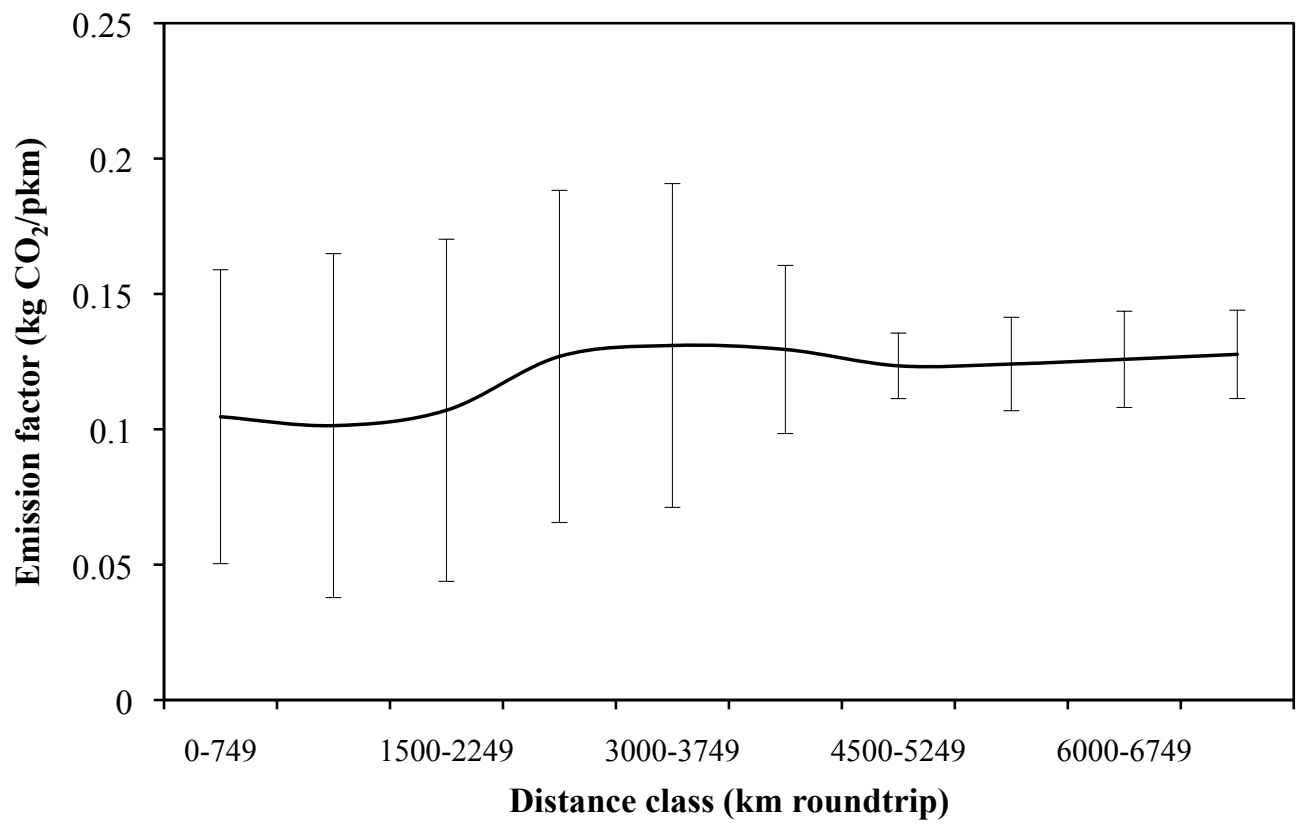

\section{Conclusion and Discussion}

This paper answered three questions: (1) is current tourism developing sustainably; (2) are current geographies/studies well equipped to assist policy makers in creating sustainable tourism development; and (3) how may the geography of tourism have to change to develop tourism sustainably. In short, the answers are: (1) tourism is not developing sustainably with respect to climate change; (2) the way in which current tourism geography is applied gives incomplete and sometimes misleading information to policy makers; and (3) sustainable development of tourism is impossible without substantial reductions of global travel distances in combination with a strong modal shift and additional improvements in energy efficiency in both transport and accommodations. These conclusions were reached by further developing older ideas from tourism geography and integrating them with some elements of transport geography; 'New' approaches include a focus on travel distance and travel time, the inclusion of all tourism (international and domestic) and a reconsideration of the nation as a basis for tourism flow data.

The first conclusion is founded in the literature $[1-3,8,9]$. Tourism related emissions are expected to continue to grow through the end of this century, and emission reductions of more than $80 \%$ are required to avoid 'dangerous' climate change. The main drivers for the environmentally unsustainable development of tourism are the increasing number of tourism trips and, on top of that, an increase of average travel speed caused by an increasing use of air transport, and resulting in an increase of average distances travelled. By 2050, tourism may cause all of the $\mathrm{CO}_{2}$ emissions globally allowable within a scenario that assumes preventing 'dangerous climate change'. This projection includes assumptions about improved technology but excludes a significant role of biofuels because the prospects for biofuels are generally estimated to be higher than can be realized in the short to medium term. The role of transport speed has been shown in the boost of distances travelled, that grow faster than the number of tourist-nights. A sustainable tourism sector should somehow embrace the idea of decoupling its growth from the growth of transport. The sector must somehow get away from the 
highest speed transport modes or put more effort into selling other properties of travel than the shortest travel time.

To answer the second question it has been shown that a spatially-based theoretical approach to tourism geography had been founded already by the 1970s, but that a lack of operationalization at the global level and the use of flawed global tourism data [33], though being a useful starting point, led to knowledge gaps and misleading information. First, all domestic tourism, approximately $80 \%$ of all global trips, is not included. Second, the data takes the nation as the basis for measurement. This basis is unfortunate as nations vary by up to eight orders of magnitude in size (geographic, population, economic), which means that data points are not consistent (e.g., compare domestic travel within China with that within Monaco, both of which are an equal record in a nation based global database). Finally, almost all tourism databases fail to provide origin-destination data and thus exclude transport volumes. We developed the GTTD using the UNWTO data for international arrivals, additional EU and Dutch data, and some known and novel general relationships or 'rules of thumb'. A linear relationship between tourist trips and GDP per capita delivered the number of domestic trips, while domestic distances were extracted from the relation between the size of a country and the average distance of domestic tourism found for EU tourism. The possible existence of a power law describing the trip frequency as function of travel distance, related to the phenomenon of distance decay, allowed for redistribution of the largest domestic markets (e.g., China, the USA) over several distance classes. Although distance decay has been demonstrated by some authors for international tourism, detailed data for Dutch holidaymakers revealed that travel time (total in-transport time) follows the power law much better than travel distance. To find this result, the relation between travel distance and average travel speed for a range of transport modes has been found from another Dutch database that describes daily mobility. Figure 3 is the first published figure to use such data, although the idea for such relations stems at least from the 1970s [15]. Finally the problem of the nation as unit of measure, has been tackled by introducing the 18 SRES world regions, which are more even and differ by less than one order of magnitude in size. Ideally, a global database should be based on standardized areas (e.g., $100 \times 100 \mathrm{~km}^{2}$ ) containing data at the origin destination level for the number of trips, transport modes, distances, and spending habits. However, such a database may reach prohibitive sizes with current computer technology [120]. Interestingly, such tourism models might be coupled to down-scaled climate models, though some climatologists doubt the accuracy of these detailed models [120].

The GTTD is based on a large set of estimates and assumptions that create uncertainty about its validity. Therefore, we recommend the start of a new line of research on the intersection of tourism and transport geography to substantiate or reject the hypotheses about travel time and distance power laws, trip generation, and accessibility. However, the conclusion of this study, that sustainable tourism will not be achieved without somehow decoupling tourism growth from tourism transport volume growth has wide support [8,9,121-125]. A reduction of tourism trip one-way distances to below $1,500 \mathrm{~km}$, affecting $20-25 \%$ of all trips, may reduce total travel distance by $57 \%$ and emissions by approximately $65 \%$. Such reductions would also allow for a modal shift from air (and car) to rail and coach, enabling a total reduction of emissions of up to $90 \%$ with current technology and at current trip numbers. This two-pronged (combined transport volume reduction and a shift to more efficient transport modes) improvement of sustainability has thus far been ignored by most scholars and policy-makers but, as we have shown in the methodological sections of this paper, probably on flawed grounds. 
A final methodological finding came from the analysis of the detailed Dutch holidaymaker data. It appeared that a 'Levy Flight' might be at work for travel time rather than travel distance. If that result is the case, this means that indeed travel speed will be the main or even the only parameter determining total distances travelled. Thus, effective mitigation policies should take reducing speed as a starting point, something also proposed by proponents of 'slow travel', although partly for different reasons [123,126,127]. It is recommended that further development of the approach to tourism geography as described above is necessary with the aims to better understand the mechanisms causing environmentally unsustainable development of tourism and to make the case for using reduced transport speeds as a policy to improve sustainable development.

In many discussions about reducing tourism transport because of its environmental impacts, there is reference to the detrimental effects of such measures on developing countries because the economy of such countries (e.g., small island nations) depends significantly on tourism. These ideas are based on a general notion that tourists always need to travel long distances to many of these developing countries and that reductions in long haul travel will always result in a reduction of the local tourism industry. However, these notions are based on an erroneous view of global tourism, which ignores most tourism trips (domestic) and assumes that a trip not taken for one destination will be lost for the whole tourism sector. Exclusion of domestic tourism causes an exaggeration of the impacts on tourism flows as including domestic tourism would dilute the impact on trips by a factor of up to 5. The idea that trips made impossible will be lost for the whole tourism sector is typical for destination-based thinking. Indeed it is correct for a specific destination. However, the incentive to travel does not depend on one specific destination, but on availability of time and income of the tourist. This means that such trips will redistribute to other destination, which thus will benefit from the measure.

Finally, our work has importance for the other, non-environmental, aspects of sustainability, such as the economic and social elements. Although we concentrated on environmental sustainability, it seems obvious that discussions about economic distribution effects and cross-cultural impacts would also likely benefit from a clear understanding of global tourism flows and the drivers causing them. Our recommendation is to do more research in establishing the economic and socio-cultural flows caused by tourism and then proceed to assess the positive and negative impacts.

\section{Acknowledgments}

First, we thank Jeroen Nawijn and Nina Delbressine for their advice and work on some statistics used for this paper. Also, we are indebted to Michael Hall and Stefan Gössling for asking us to write this paper and for their very constructive comments on a draft version of this paper and assistance with writing proper English. Finally we thank the two anonymous reviewers for their constructive comments.

\section{Conflict of Interest}

The authors declare no conflict of interest. 


\section{References and Notes}

1. Scott, D.; Peeters, P.; Gössling, S. Can tourism deliver its 'aspirational' greenhouse gas emission reduction targets? J. Sustain. Tour. 2010, 18, 393-408.

2. UNWTO-UNEP-WMO. Climate Change and Tourism: Responding to Global Challenges; UNWTO: Madrid, Spain, 2008.

3. Bows, A.; Anderson, B.; Peeters, P.M. Air transport, climate change and tourism. Tour. Hosp. Plan. Dev. 2009, 6, 7-20.

4. World Travel\&Tourism Council (WTTC). Climate Change. A Joint Approach to Addressing the Challenge; WTTC: London, UK, 2010.

5. Chiesa, T.; Gautam, A. Towards a Low Carbon Travel \& Tourism Sector; World Economic Forum: Geneva, Switzerland, 2009.

6. Cabrini, L.; Simpson, M.; Scott, D. From Davos to Copenhagen and Beyond: Advancing Tourism's Response to Climate Change; Unwto Background Paper; UNWTO: Madrid, Spain, 2009.

7. Gössling, S.; Hall, C.M.; Peeters, P.; Scott, D. The future of tourism: Can tourism growth and climate policy be reconciled? A climate change mitigation perspective. Tour. Recreat. Res. 2010, 35, 119-130.

8. Peeters, P.M.; Dubois, G. Tourism travel under climate change mitigation constraints. J. Transp. Geogr. 2010, 18, 447-457.

9. Dubois, G.; Ceron, J.P.; Peeters, P.; Gössling, S. The future tourism mobility of the world population: Emission growth versus climate policy. Transp. Res. A 2011, 45, 1031-1042.

10. Geography World What is Geography? Definition of Geography on the Web. Geography World, 2011. Available online: http://geographyworldonline.com/definition.html (accessed on 20 June 2011).

11. Geography; Answers.com: Jerusalem, Israel, 2011. Available online: http://www.answers. com/geography (accessed on20 June 2011).

12. Williams, S. Tourism Geography: A New Synthesis, 2nd ed.; Taylor \& Francis: London, UK, 2009.

13. Mitchell, L.S.; Murphy, P.E. Geography and tourism. Ann. Tour. Res. 1991, 18, 57-70.

14. Pearce, D. Tourism Today. A Geographical Analysis, 2nd ed.; Longman Scientific \& Technical: Essex, UK, 1995; p. 202.

15. Miossec, J.-M. Elements pour une theorie de l'espace touristique. Les Cahiers du Tourisme 1976, Serie $C, 1-63$.

16. Williams, A.V.; Zelinsky, W. On some patterns in international tourist flows. Econ. Geogr. 1970, 46, 549-567.

17. Butler, R.W. The concept of a tourist area cycle of evolution: Implications for management of resources. Can. Geogr. 1980, 24, 5-12.

18. Hall, C.M. Space-time accessibility and talc: The role of geographies of spatial interaction and mobility in contributing to an improved understanding of tourism. In The Tourism Area Life Cycle, Conceptual and Theoretical Issues; Butler, R.W., Ed.; Channel View Press: Clevedon, UK, 2006; volume 2, pp. 83-100.

19. Hall, C.; Page, S. The geography of Tourism and Recreation: Environment, Place and Space, 2nd ed.; Routeledge: London, UK, 2002; p. 399. 
20. Gössling, S.; Hall, C.M. Conclusion. Wake up ... This is serious. In Tourism \& Global Environmental Change. Ecological, Social, Economic and Political Interrelationships, Gössling, S., Hall, C.M., Eds.; Routledge: London, UK, 2006; Volume 4, pp. 305-320.

21. Cooper, C. Tourism: Principles and Practice; Pearson Education Limited: Harlow, UK, 2008.

22. Budd, L.C.S. On being aeromobile: Airline passengers and the affective experiences of flight. J. Transp. Geogr. 2011, 19, 1010-1016.

23. Hall, C.M. Tourism: Rethinking the Social Science of Mobility; Pearson Education Limited: London, UK, 2005.

24. Mayor, K.; Tol, R.S.J. The impact of european climate change regulations on international tourist markets. Transp. Res. Part D 2010, 15, 26-36.

25. Veryard, D. Study of International Visitor Flows and Greenhouse Gas Emissions for a Template to Examine the Impact on Apec Economies of Future Market-Based Measures Applying to International Transport; GHD Meyrick: Canberra, Australia, 2009.

26. Mayor, K.; Tol, R.S.J. The impact of the UK aviation tax on carbon dioxide emissions and visitor numbers. Transp. Policy 2007, 14, 507-513.

27. Gössling, S.; Peeters, P.; Scott, D., Consequences of climate policy for international tourist arrivals in developing countries. Third World Q. 2008, 29, 873-901.

28. Becken, S.; Lennox, J. Implications of a long-term increase in oil prices for tourism. Tour. Manag. 2012, 33, 133-142.

29. Anger, A. Including aviation in the european emissions trading scheme: Impacts on the industry, $\mathrm{CO}_{2}$ emissions and macroeconomic activity in the EU. J. Air Transp. Manag 2010, 16, 100-105.

30. UNWTO. 2007 Edition Tourism Market Trends. World Overview; 2006 Ed.; World Tourism Organisation: Madrid, Spain, 2008.

31. UNWTO. UNWTO World Tourism Barometer; UNWTO: Madrid, Spain, 2009; Volume 7, nr. 2.

32. China Statistical Yearbook-2008. National Bureau of Statistics of China: Beijing, China, 2008. Available online: http:/www.stats.gov.cn/tjsj/ndsj/2008/indexee.htm (accessed on 12 Septermber 2009).

33. UNWTO World Statistics Day; UNWTO World Tourism Organization: Madrid, Spain. Available online: http://statistics.unwto.org/en/content/world-statistics-day (accessed on 22 October 2011).

34. UNWTO. Compendium of tourism statistics (2005-2009); UNWTO: Madrid, Spain, 2011. Available online: http://www.wtoelibrary.org/content/v486k6/?v=search (accessed on 28 July 2011).

35. Xu, J.; Yao, L.; Mo, L. Simulation of low-carbon tourism in world natural and cultural heritage areas: An application to Shizhong district of Leshan city in China. Energy Policy 2011, 39, 4298-4307.

36. Dwyer, L.; Forsyth, P.; Dwyer, W. Tourism Economics and Policy; Channel View Publications: Bristol, UK, 2010.

37. Rodrigue, J.P.; Comtois, C.; Slack, B. The Geography of Transport Systems; Routledge: London, UK, 2006. 
38. Bigano, A.; Hamilton, J.M.; Lau, M.; Tol, R.S.J.; Zhou, Y. A Global Database of Domestic and International Tourist Numbers at National and Subnational Level; Working Paper FNU-54; Research Unit Sustainability and Global Change, Hamburg University and Centre for Marine and Atmospheric Science: Hamburg, Germany, 2004.

39. UNWTO. Compendium of Tourism Statistics (2007 Edition); World Tourism Organisation: Madrid, Spain, 2007.

40. UNWTO. UNWTO World Tourism Barometer (English Version); UNWTO: Madrid, Spain, 2011; volume 9, pp. 1-57.

41. IMAGE-team. The IMAGE 2.2 Implementation of the SRES Scenarios. A Comprehensive Analysis of Emissions, Climate Change and Impacts in the 21st Century; CD-ROM 500110001 (former 481508018); National Institute for Public Health and the Environment: Bilthoven, The Netherlands, 2006.

42. Swartz, K.L. Great Circle Mapper; 2010. Available online: http://gc.kls2.com/ (accessed on 22 January 2010).

43. Central Intelligence Agency (CIA). The World Factbook 2005; ISSN 1553-8133; CIA: Washington, DC, USA, 2005.

44. Central Intelligence Agency (CIA). The World Factbook 2008; ISSN 1553-8133; CIA: Washington, DC, USA, 2008.

45. Zahavi, Y.; Talvitie, A. Regularities in travel time and money expenditures. Transp. Res. Record 1980, 750, 13-19.

46. Zahavi, Y.; Lang, P.J. Traveltime Budgets and Mobility in Urban Areas; US Department of Transportation: Washington, DC, USA, 1974.

47. Zahavi, Y. The Unified Mechanism of Travel (UMOT) Model; 1976. Available online: http://www.surveyarchive.org/Zahavi/TheUMOTModel.pdf (accessed on 9 November 2011).

48. Hägerstrand, T. What about people in regional science? Papers Reg. Sci. 1970, 24, 6-21.

49. Levinson, D.; Kumar, A. Activity, travel, and the allocation of time. J. Am. Plan. Assoc. 1995, $61,458-470$.

50. Hupkes, G. The law of constant travel time and trip-rates. Futures 1982, 14, 38-46.

51. Arentze, T.A.; Timmermans, H.J.P. A dynamic model of time-budget and activity generation: Development and empirical derivation. Transp. Res. Part C 2011, 19, 242-253.

52. Schäfer, A. Regularities in travel demand: An international perspective. J. Transp. Stat. 2000, 3, $1-31$.

53. Schäfer, A. The global demand for motorized mobility. Transp. Res. A 1998, 32, 445-477.

54. Schäfer, A.; Victor, D.G. The future mobility of the world population. Transp. Res. A 2000, 34, 171-205.

55. Shu-wei, Z.; Ke-jun, J.; De-shun, L. Macro-level transport modal split model: Theory and application in China. In Proceedings of International Conference on Management Science and Engineering, ICMSE'06, Lille, France, 5-7 October 2006; pp. 2033-2038.

56. Metz, D. The Limits to Travel. How Far will We Go? Earthscan: London, UK, 2008; p. 164.

57. Banister, D. The trilogy of distance, speed and time. J. Transp. Geogr. 2011, 19, 950-959. 
58. Mokhtarian, P.L.; Chen, C. TTB or not TTB, that is the question: A review and analysis of the empirical literature on travel time (and money) budgets. Transp. Res. Part A 2004, 38, 643-675.

59. Kölbl, R.; Helbing, D. Energy and scaling laws in human travel behaviour. New J. Phys. 2003, 5, 48:1-48:12.

60. Lin, C.-H.; Morais, D.B. The spatial clustering effect of destination distribution on cognitive distance estimates and its impact on tourists' destination choices. Travel Tour. Mark. 2009, 25, 382-397.

61. Projectteam MON. Mobiliteitsonderzoek Nederland 2005. Het Onderzoek; Ministerie van Verkeer en Waterstaat, Rijkswaterstaat Adviesdienst Verkeer en Vervoer: Den Haag, The Netherlands, 2006.

62. Mitchell, L.S. Tourism research in the united states: A geographic perspective. GeoJournal 1984, 9, 5-15.

63. Fotheringham, A.S. Spatial structure and distance-decay parameters. Ann. Assoc. Am. Geogr. 1981, 71, 425-436.

64. Wilson, A.G. The use of entropy maximising models, in the theory of trip distribution, mode split and route split. J. Transp. Econ. Policy 1969, 111, 108-126.

65. Ravenstein, E.G. The laws of migration. Second paper. J. R. Stat. Soc. 1889, 52, 241-305.

66. Ravenstein, E.G. The laws of migration. J. Stat. Soc. Lond. 1885, 48, 167-235.

67. Eldridge, J.D.; Jones, J.P. Warped space: A geography of distance decay. Prof. Geogr. 1991, 43, 500-511.

68. Tobler, W.R. A computer movie simulating urban growth in the Detroit region. Econ. Geogr. 1970, 46, 234-240.

69. Tobler, W. Thirty five years of computer cartograms. Ann. Assoc. Am. Geogr. 2004, 94, 58-73.

70. Mckercher, B.; Lew, A. Distance decay and the impact of effective tourism exclusion zones on international travel flows. J. Travel Res. 2003, 42, 159-165.

71. McKercher, B.; Chan, A.; Lam, C. The impact of distance on international tourist movements. J. Travel Res. 2008, 47, 208-224.

72. Smith, S. US vacation travel patterns: Correlates of distance decay and the willingness to travel. Leis. Sci. 1985, 7, 151-174.

73. Christaller, W. Some considerations of tourism location in Europe: The peripheral regions-underdeveloped countries-recreation areas. Papers Reg. Sci. 1964, 12, 95-105.

74. Hall, C. Time, space, tourism and social physics. Tour. Recreat. Res. 2005, 30, 93-98.

75. Ball, P. Critical Mass; Farrar, Strauss and Giroux: New York, NY, USA, 2004.

76. Banerjee, A.; Yakovenko, V.M. Universal patterns of inequality. New J. Phys. 2010, 12, 075032.

77. Clauset, A.; Shalizi, C.R.; Newman, M.E.J. Power-law distributions in empirical data. SIAM Rev. 2009, 51, 661-703.

78. James, A.; Plank, M.J. On fitting power laws to ecological data. Arxiv Prepr. 2007, arXiv:0712.0613v1.

79. Newman, M. Power laws, Pareto distributions and Zipf's law. Contemp. Phys. 2005, 46, 323-351.

80. Sornette, D. Critical Phenomena in Natural Sciences: Chaos, Fractals, Selforganization, and Disorder: Concepts and Tools, 2nd ed.; Springer: Berlin, Germany, 2006. 
81. Stanley, H.E.; Amaral, L.A.N.; Buldyrev, S.V.; Gopikrishnan, P.; Plerou, V.; Salinger, M.A. Self-organized complexity in economics and finance. Prod. Natl. Acad. Sci. USA 2002, 99, 2561-2565.

82. Coelho, R.; Richmond, P.; Barry, J.; Hutzler, S. Double power laws in income and wealth distributions. Phys. A 2008, 387, 3847-3851.

83. Mandelbrot, B.B. Fractals and Scaling in Finance: Discontinuity, Concentration, Risk; Springer Verlag: New York, NY, USA, 1997.

84. Mandelbrot, B. The variation of certain speculative prices. J. Bus. 1963, 36, 394-419.

85. Brockmann, D.; Hufnagel, L.; Geisel, T. The scaling laws of human travel. Nature 2006, 439, 462-465.

86. Gonzalez, M.C.; Hidalgo, C.A.; Barabasi, A.-L. Understanding individual human mobility patterns. Nature 2008, 453, 779-782.

87. Humphries, N.E.; Queiroz, N.; Dyer, J.R.M.; Pade, N.G.; Musyl, M.K.; Schaefer, K.M.; Fuller, D.W.; Brunnschweiler, J.M.; Doyle, T.K.; Houghton, J.D.R.; et al. Environmental context explains Lévy and Brownian movement patterns of marine predators. Nature 2010, 465, 1066-1069.

88. Viswanathan, G.M. Ecology: Fish in Lévy-flight foraging. Nature 2010, 465, 1018-1019.

89. James, A.; Plank, M.J.; Edwards, A.M. Assessing Lévy walks as models of animal foraging. J. R. Soc. Interface 2011, in press.

90. Peeters, P.M.; van Egmond, T.; Visser, N. European Tourism, Transport and Environment. Final version; NHTV CSTT: Breda, The Netherlands, 2004.

91. NBTC-NIPO. Continu Vakantie Onderzoek (continuous holiday survey); NBTC-NIPO: Amsterdam, The Netherlands, 2011. Available online: http://www.nbtcniporesearch.nl/nl/ Home/Producten-en-diensten/cvo.htm (accessed on 5 July 2011).

92. De Bruijn, K.; Dirven, R.; Eijgelaar, E.; Peeters, P. Travelling Large in 2009. The Carbon Footprint of Dutch Holidaymakers in 2009 and the Development Since 2002; NHTV University for Applied Sciences in collaboration with NBTC-NIPO Research: Breda, The Netherlands, 2010.

93. Nicolau, J.L.; Más, F.J. The influence of distance and prices on the choice of tourist destinations: The moderating role of motivations. Tour. Manag. 2006, 27, 982-996.

94. Daan, S.; Deerenberg, C.; Dijkstra, C. Increased daily work precipitates natural death in the Kestrel. J. Anim. Ecol. 1996, 539-544.

95. Masman, D.; Daan, S.; Dijkstra, C. Time allocation in the Kestrel (falco tinnunculus), and the principle of energy minimization. J. Anim. Ecol. 1988, 411-432.

96. Masman, D.; Dijkstra, C.; Daan, S.; Bult, A.; Reyer, U. Energetic limitation of avian parental effort: Field experiments in the Kestrel (falco tinnunculus). J. Evol. Biol. 1989, 2, 435-455.

97. Peeters, P.M.; Middel, J. Historical and Future Development of Air Transport Fuel Efficiency. In Proceedings of an International Conference on Transport, Atmosphere and Climate (tac), Oxford, UK, 26-29 June 2006, Sausen, R., Blum, A., Lee, D.S., Brüning, C., Eds.; DLR Institut für Physic der Atmosphäre: Oberpfaffenhoven, Germany, 2007; pp. $42-47$.

98. CBS Statline; CBS: The Hague, The Netherlands, 2011. Available online: http://statline.cbs.nl/ StatWeb/start.asp?LA=nl\&DM=SLNL\&lp=Search/Search (accessed on 1 Septermber 2011).

99. Mayor, K.; Tol, R.S.J. Scenarios of carbon dioxide emissions from aviation. Glob. Environ. Change 2010, 20, 65-73. 
100. Lee, D.; Pitari, G.; Grewe, V.; Gierens, K.; Penner, J.; Petzold, A.; Prather, M.; Schumann, U.; Bais, A.; Berntsen, T. Transport impacts on atmosphere and climate: Aviation. Atmos. Environ. 2010, 44, 4678-4734.

101. Åkerman, J. Sustainable air transport-On track in 2050. Transp. Res. D 2005, 10, 111-126.

102. Peeters, P.; Williams, V.; de Haan, A. Technical and management reduction potentials. In Climate Change and Aviation: Issues, Challenges and Solutions, Gössling, S., Upham, P., Eds. Earthscan: London, UK, 2009; pp. 293-307.

103. Air Transport Action Group (ATAG). Powering the Future of Flight. The Six Easy Steps to Growing a Viable Aviation Biofuels Industry; web version; ATAG: Geneva, Switzerland, 2011.

104. The Air Transport Association (IATA). The IATA Technology Roadmap Report; IATA: Montreal, Canada, 2009.

105. Aviation Global Deal Group: A Sectoral Approach to Addressing International Aviation Emissions; Discussion note 2.0, 9 June 2009; AGD: London, UK, 2009. Available online: http://www.agdgroup.org/pdfs/090609_AGD_Discussion_Note_2.0.pdf (accessed on 22 December 2009).

106. ICAO. Comparison of life cycle GHG emissions from select alternative jet fuels, caaf/09-ip/6. In Conference on Aviation and Alternative Fuels, ICAO: Rio de Janeiro, Brazil, 2009.

107. Bailis, R.E.; Baka, J.E. Greenhouse gas emissions and land use change from Jatropha curcas-based jet fuel in Brazil. Environ. Sci. Technol. 2010, 44, 8684-8691.

108. Ariza-Montobbio, P.; Lele, S. Jatropha plantations for biodiesel in Tamil Nadu, India: Viability, livelihood trade-offs, and latent conflict. Ecol. Econ. 2010, 70, 189-195.

109. Findlater, K.M.; Kandlikar, M. Land use and second-generation biofuel feedstocks: The unconsidered impacts of Jatropha biodiesel in Rajasthan, India. Energy Policy 2011, 39, 3404-3413.

110. Gerbens-Leenes, W.; Hoekstra, A.Y.; van der Meer, T.H. The water footprint of bioenergy. Proc. Natl. Acade. Sci. USA 2009, 106, 10219-10223.

111. Kant, P.; Wu, S. The extraordinary collapse of Jatropha as a global biofuel. Environ. Sci. Technol. 2011, 45, 7114-7115.

112. Sanderson, K. Wonder weed plans fail to flourish. Nature 2009, 461, 328-329.

113. Achten, W.; Verchot, L.; Franken, Y.; Mathijs, E.; Singh, V.; Aerts, R.; Muys, B. Jatropha bio-diesel production and use. Biomass Bioenergy 2008, 32, 1063-1084.

114. Edgerton, D. The Shock of the Old; Profile Books Ltd.: London, UK, 2007.

115. Edgerton, D. The charge of technology. Nature 2008, 455, 1030-1031.

116. Hall, C.M. Degrowing tourism: Décroissance, sustainable consumption and steady-state tourism. Anatolia 2009, 20, 46-61.

117. Hall, C.M. Changing paradigms and global change: From sustainable to steady-state tourism. Tour. Recreat. Res. 2010, 35, 131-143.

118. OECD. Oecd Tourism Trends and Policies 2010; ISBN 978-92-64-07742-3; OECD: Paris, France, 2010.

119. De Bruijn, K.; Dirven, R.; Eijgelaar, E.; Peeters, P. Travelling Large in 2010. The Carbon Footprint of Dutch Tourism in 2010 and Developments Since 2002; NHTV University for Applied Sciences in collaboration with NBTC-NIPO Research: Breda, The Netherlands, 2011, in press. 
120. Kerr, R.A. Vital details of global warming are eluding forecasters. Science 2011, 334, 173-174.

121. Kallis, G. In defence of degrowth. Ecol. Econ. 2011, 70, 873-880.

122. Peeters, P. Transport technology, tourism and climate change. In Tourism and the Implications of Climate Change: Issues and Actions, Schott, C., Ed.; Emerald: Bingley, UK, 2010; Volume 3, pp. 67-90.

123. Dickinson, J.E. Adapting tourism for a lower carbon future: A slow travel approach. In Transport and Tourism. Challenges, Issues and Conflicts. Proceedings of the Travel and Tourism Research Association Europe, Annual Conference, Rotterdam; Breda, The Netherlands, 22-24 April 2009; Landré, M., Ed.; TTRA: Breda, The Netherlands, 2009; pp. 32-45.

124. Peeters, P.; Szimba, E.; Duijnisveld, M. Major environmental impacts of european tourist transport. J. Transp. Geogr. 2007, 15, 83-93.

125. Hall, C.M. Policy learning and policy failure in sustainable tourism governance: From first- and second-order to third-order change? J. Sustain. Tour. 2011, 19, 649-671.

126. Lumsdon, L.M.; McGrath, P. Developing a conceptual framework for slow travel: A grounded theory approach. J. Sustain. Tour. 2010, 19, 265-279.

127. Dickinson, J.; Lumsdon, L. Slow Travel and Tourism; Earthscan: London, UK, 2010.

(C) 2012 by the authors; licensee MDPI, Basel, Switzerland. This article is an open access article distributed under the terms and conditions of the Creative Commons Attribution license (http://creativecommons.org/licenses/by/3.0/). 